Article

\title{
An Analysis of the Occurrence Probabilities of Wet and Dry Periods through a Stochastic Monthly Rainfall Model
}

\author{
Tommaso Caloiero $^{1}$, Beniamino Sirangelo ${ }^{2}$, Roberto Coscarelli ${ }^{3}$ and Ennio Ferrari ${ }^{4, *}$ \\ 1 National Research Council-Institute for Agricultural and Forest Systems in Mediterranean (CNR-ISAFOM), \\ Via Cavour 4/6, 87036 Rende (Cs), Italy; tommaso.caloiero@isafom.cnr.it \\ 2 Department of Environmental and Chemical Engineering (DIATIC), University of Calabria, Via P. Bucci 41C, \\ 87036 Rende (CS), Italy; beniamino.sirangelo@unical.it \\ 3 National Research Council-Research Institute for Geo-Hydrological Protection (CNR-IRPI), \\ Via Cavour 4/6, 87036 Rende (Cs), Italy; coscarelli@irpi.cnr.it \\ 4 Department of Computer Engineering, Modeling, Electronics, and Systems Science (DIMES), \\ University of Calabria, Via P. Bucci 41C, 87036 Rende (CS), Italy \\ * Correspondence: ennio.ferrari@unical.it; Tel.: +39-0984-496618
}

Academic Editor: Ataur Rahman

Received: 27 September 2015; Accepted: 22 January 2016; Published: 28 January 2016

\begin{abstract}
Stochastic simulators can effectively generate the intrinsic variability of the rainfall process, which is an important issue in the analysis of the projections uncertainties. In this paper, a procedure for stochastic modeling of precipitation at monthly scale is proposed. The model adopts variable transformations, which are finalized to the deseasonalization and the Gaussianization of the monthly rainfall process, and includes a procedure for testing the autocorrelation. The model was applied to a homogeneous database of monthly rainfall values registered in 12 rain gauges in the region of Calabria (Southern Italy). After the estimation of the model parameters, a set of $10^{4}$ years of monthly rainfall for each rain gauge was generated by means of a Monte Carlo technique. Then, dry and wet periods were analyzed through the application of the standardized precipitation index (SPI). Some results, confirmed through the application of the drought severity index (DSI), showed that the proposed model provided a good representation of the monthly rainfall for the considered rain gauges. Moreover, the results of the SPI application indicate a greater probability of dry conditions than wet conditions, especially when long-term precipitation patterns are considered.
\end{abstract}

Keywords: monthly rainfall; stochastic model; dry and wet periods; Calabria

\section{Introduction}

A natural temporary imbalance of water availability, consisting of persistent lower-than-average or higher-than-average precipitation, can cause extreme dry and wet conditions that adversely impact agricultural yields, water resources, infrastructure and human systems. For example, dry conditions have severe consequences because they can give rise to agricultural yield losses and water shortages [1,2]. They also damage natural ecosystems [3,4] and forestry $[5,6]$ and lead to soil degradation and desertification [7,8], social alarm [9], famine and impoverishment [10,11]. Conversely, wet conditions can cause flood, damage crops, reduce yields, and contribute to groundwater contamination [12-17]. For these reasons, the analysis of the distribution of dry and wet periods has always been a concern for researchers [18-26]. In general, climate anomalies are quantitatively assessed through indices that allow scientists to characterize them in terms of intensity, duration, frequency, recurrence probability and spatial extent $[27,28]$. Among the several indices, two of the most commonly used are the standardized precipitation index (SPI), which transforms monthly precipitation 
time series into a standardized normal distribution, and the drought severity index (DSI), which uses accumulated monthly precipitation anomalies. In particular, the SPI has found widespread application in different countries of the world [29-35], in the Mediterranean basin [36-38] and also in Central [39] and Southern Italy [40-46]. The SPI is easier to calculate than more complex indices because it is based on precipitation alone for estimating wet or dry conditions [38,47]. Moreover, these conditions can be monitored by the SPI on a variety of time scales from sub-seasonal to inter-annual scales [43].

Generally, the probabilistic structure of dry and wet periods, especially with a long duration, cannot be properly investigated due to the limited number of events in the historical series [48]. Moreover, complete data are strictly required to perform the analysis of wet and dry periods, because missing values may significantly influence estimates of event duration and the character of their alternation [49]. In order to overcome such a difficulty, the probabilistic behavior of dry and wet periods characteristics can be derived analytically, assuming a given stochastic structure of the underlying hydrological and meteorological series [24,50-59]. This has led to the development of stochastic models frequently used to produce long rainfall series that are statistically similar to historical records (e.g., [60]). In particular, mathematical modeling of hydrological data as a stochastic process is of interest to a variety of hydrological areas such as flood forecasting, reservoir operations and agricultural planning [61-63]. Current state-of-the-art stochastic precipitation models at a single site or for multiple sites can reproduce a wide range of statistics from hourly scale extremes to larger aggregation periods [64-75]. In particular, numerous approaches for the stochastic modeling of daily rainfall data are available in the hydrological and climatological literature [76-84]. These models are widely used because they are easy to formulate and fast to implement [26]. Stochastic modeling also allows for accounting of potentially wider range of conditions that may not be necessarily represented in poorly sampled data. Moreover, by means of stochastic simulators, effectively intrinsic variability, not associated with forced signals (e.g., by global warming), can be generated; this variability is important because it places uncertainties on projections. However, very little work has been done on stochastic generation of monthly rainfall data [85] because in the past low attention was paid to totals at this time aggregation.

The aims of this study are:

(a) to propose a stochastic procedure for modeling precipitation at monthly scale;

(b) to analyze dry and wet periods through the application of the standardized precipitation index (SPI) to a set of monthly rainfall series generated by the proposed model through a Monte Carlo procedure. These results have been compared with the ones obtained through the application of the drought severity index (DSI).

In particular, the model has been applied to a set of monthly rainfall series observed in Southern Italy (the region of Calabria).

\section{Methodology}

\subsection{Standardized Precipitation Index}

In this study, dry and wet periods were expressed using the SPI [86] on different time scales. Indeed, it is generally agreed that the SPI on short-term scales (e.g., 3 or 6 months) describes drought affecting vegetation and agricultural practices, while on long-term scales (e.g., 12 or 24 months) it is a broad proxy for water resource management [40-42]. A detailed description of the SPI has been proposed previously [87]. Although a classification restricted only to drought periods has been originally proposed [86], it has become customary to use the index to classify wet periods as well. Table 1 reports the climatic classification according to the SPI, provided by the National Drought Mitigation Center (NDMC). 
Table 1. Climate classification according to the SPI values [86].

\begin{tabular}{ccc}
\hline SPI Value & Class & Probability (\%) \\
\hline $\mathrm{SPI} \geqslant 2.0$ & Extremely wet & 2.3 \\
$1.5 \leqslant \mathrm{SPI}<2.0$ & Severely wet & 4.4 \\
$1.0 \mathrm{SPI}<1.5$ & Moderately wet & 9.2 \\
$0.0 \mathrm{SPI}<1.0$ & Mildly wet & 34.1 \\
$-1.0 \leqslant \mathrm{SPI}<0.0$ & Mild drought & 34.1 \\
$-1.5 \leqslant \mathrm{SPI}<-1.0$ & Moderate drought & 9.2 \\
$-2.0 \leqslant \mathrm{SPI}<-1.5$ & Severe drought & 4.4 \\
$\mathrm{SPI}<-2.0$ & Extreme drought & 2.3 \\
\hline
\end{tabular}

Despite its widespread application, some limitations of the SPI calculation must be addressed. In fact, as evidenced by a previous study [88], the SPI is an index with several univariate probability distribution recommendations that typically rely on the Kolmogorov-Smirnov test. However, this test has been shown to be relatively insensitive in previous statistical analyses [89] and requires time-consuming Monte Carlo simulation of critical values when applied to distributions derived from the data $[90,91]$. Moreover, probability distribution fitting for the SPI is also complicated by the presence of periods with zero precipitation, as has been previously described [92], and current procedures do not adequately capture the likelihood of zero precipitation events.

\subsection{Drough Severity Index (DSI)}

Based on the accumulated monthly rainfall deficit concept of a previous report [93], the drought severity index (DSI) is evaluated through the precipitation anomalies (mm) defined in this work with reference to the 1961-1990 mean [25,94,95]. Two indices, DSI3 and DSI6, can be used by means of different termination rules. Considering the DSI3, if the precipitation anomaly in month $t$ is denoted as $X_{t}$ and is negative and the precipitation in the preceding 3-month period (i.e., $t-1, t-2, t-3$ ) is also lower than its mean, then a drought sequence can start. In this case, the positive value assumed for DSI3 is proportional to the deficit in month $t$. Considering the next month $(t+1)$, if its precipitation deficit is $-Y \mathrm{~mm}$, and the mean monthly precipitation total for the preceding 3 months has not been exceeded, then DSI3 for the month $(t+1)$ is $X+Y$. On the contrary, if the precipitation anomaly is positive, the drought can continue provided that the 3-monthly mean total has not been exceeded. The termination of a drought event occurs when the 3-monthly mean total is exceeded, thus assigning a value of zero to DSI3. DSI6 is calculated identically, using the 6-month mean to identify drought termination. In order to allow comparisons between different rain gauges, the DSI values can be standardized by dividing the absolute deficit by the site mean annual precipitation, and then multiplying by 100 , thus expressing the accumulated precipitation deficit as a percentage of the annual mean total precipitation.

\subsection{Stochastic Modelling of Monthly Rainfall}

Let $H_{i, j}$ be the sequence of random variables describing the monthly total rainfall, where $j$ represents the month and $i$ represents the year, counted from a non-specified origin $i=0$. Defined $N_{j}$ as the number of days of the $j$-month and $I_{0}$ as a generic reference value of the daily rainfall, the dimensionless random variables,

$$
X_{i, j}=\frac{H_{i, j}}{N_{j} I_{0}}
$$

indicate a sequence that can be described as a discrete cyclostationary parameter stochastic process with period $P$ equal to 12 (months).

The model proposed in this paper is useful to describe pluviometric regimes in which there is a scarce probability that the $H_{i, j}$ values should be equal to zero. With this condition, it can be assumed 
that, for $X_{i, j}>0$ and, by adopting the transformation $Y_{i, j}=X_{i, j}^{\lambda}$ for $\lambda>0$, the sequence of random variables $Z_{k}$ :

$$
Z_{k}=\frac{Y_{i, j}-\mu_{Y, j}}{\sigma_{Y, j}} \text { with } k=12 i+j
$$

is a standardized stationary Gaussian stochastic process.

The two functions $\mu_{Y, j}=E_{i}\left(Y_{i, j}\right)$ and $\sigma_{Y, j}=\sqrt{E_{i}\left(Y_{i, j}^{2}\right)-\mu_{Y, j}^{2}}$ are appointed to the deseasonalization of the monthly rainfall process, while the transformation $Y_{i, j}=X_{i, j}^{\lambda}$ is finalized to the Gaussianization of the same process. The mean $\mu_{Y, j}$ and the variance $\sigma_{Y, j}^{2}$ functions can be described by means of the truncated Fourier series:

$$
\begin{gathered}
\mu_{Y, j} \cong \widetilde{\mu}_{Y, j}=\frac{1}{2} a_{0}^{(\mu)}+\sum_{m=1}^{N_{h}^{(\mu)}}\left[a_{m}^{(\mu)} \cos \left(\frac{\pi}{6} j m\right)+b_{m}^{(\mu)} \sin \left(\frac{\pi}{6} j m\right)\right] \\
\sigma_{Y, j}^{2} \cong \widetilde{\sigma}_{Y, j}^{2}=\frac{1}{2} a_{0}{ }^{\left(\sigma^{2}\right)}+\sum_{m=1}^{N_{h}^{\left(\sigma^{2}\right)}}\left[a_{m}^{\left(\sigma^{2}\right)} \cos \left(\frac{\pi}{6} j m\right)+b_{m}^{\left(\sigma^{2}\right)} \sin \left(\frac{\pi}{6} j m\right)\right]
\end{gathered}
$$

where $N_{h}^{(\mu)}$ and $N_{h}^{\left(\sigma^{2}\right)}$ are the number of harmonics used for the mean and variance functions, respectively, and $a_{0}^{(\cdot)}, a_{m}^{(\cdot)}, b_{m}^{(\cdot)}$ are the Fourier coefficients for each of the mean and variance functions. Given a fixed value of the parameter $\lambda$ and considering a period of $N$ years, on the basis of a sample of observed monthly rainfall, $h_{i, j}$, it is possible to evaluate a transformed sample $y_{i, j}=x_{i, j}^{\lambda}$. The parameters $a_{0}^{(\mu)}, a_{m}^{(\mu)}, b_{m}^{(\mu)}$ of the function $\tilde{\mu}_{Y, j}$, for a fixed number of harmonics $N_{h}^{(\mu)}$, can then be estimated with the use of the least squares method by minimizing the function expressed by the following equation:

$$
S_{\mu}^{2}\left(a_{0}^{(\mu)}, a_{1}^{(\mu)}, b_{1}^{(\mu)}, \ldots\right)=\sum_{i=0}^{N-1} \sum_{j=1}^{12}\left[y_{i, j}-\frac{1}{2} a_{0}^{(\mu)}-\sum_{m=1}^{N_{h}^{(\mu)}} f_{\mu}\left(j, m ; a_{m}^{(\mu)}, b_{m}^{(\mu)}\right)\right]^{2}
$$

where $f_{\mu}\left(j, m ; a_{m}^{(\mu)}, b_{m}^{(\mu)}\right)=a_{m}^{(\mu)} \cos (j m \pi / 6)+b_{m}^{(\mu)} \sin (j m \pi / 6)$.

The estimation of the coefficients for the truncated Fourier series expansion of the mean function can be performed by solving a system of $1+2 N_{h}^{(\mu)}$ linear algebraic equations in $1+2 N_{h}^{(\mu)}$ unknowns, obtained by equaling to zero the partial derivatives of $S_{\mu}^{2}\left(a_{0}^{(\mu)}, a_{1}^{(\mu)}, b_{1}^{(\mu)}, \ldots\right)$, with respect to $a_{0}^{(\mu)}, a_{m}^{(\mu)}, b_{m}^{(\mu)}$. Rarely, i.e. when the temporal span of the sample is a multiple of the period P and when the series do not have any missing monthly data, the trigonometric interpolation theory provides the estimations of the coefficients $a_{0}^{(\mu)}, a_{m}^{(\mu)}, b_{m}^{(\mu)}$ in explicit form.

An analogous procedure can be performed for the estimation of the function $\widetilde{\sigma}_{Y, j}^{2}$, for a fixed number of harmonics $N_{h}^{\left(\sigma^{2}\right)}$.

The estimation of the number of harmonics to be used for the mean and for the variance should be done by testing both the hypotheses $H_{0}^{(\mu)}$ and $H_{0}^{\left(\sigma^{2}\right)}$ that the sample mean and variance, $m_{Y, j}$ and $s_{Y, j}^{2}$, derive from statistical Gaussian universes with mean and variance respectively equal to $\tilde{\mu}_{Y, j}$ and $\tilde{\sigma}_{Y, j}^{2}$. Thus, by assuring a parameter parsimony criterion, and given a fixed value of the parameter $\lambda$, the number of harmonics can be detected as the smallest numbers that give values of $\tilde{\mu}_{Y, j}$ and $\widetilde{\sigma}_{Y, j}^{2}$, for which $H_{0}^{(\mu)}$ and $H_{0}^{\left(\sigma^{2}\right)}$ cannot be rejected with a specified significance level $\alpha$.

The extremes of the non-rejection intervals of the tests can be easily evaluated [96]. In fact, given that $Y_{i, j}$ are Gaussian variables, the distributions of the sample means follow a Student's law and the 
sample variances are distributed following a gamma distribution, with scale and shape parameters equals to 2 and $\left(N_{j}-1\right) / 2$, respectively.

The procedure for identifying the number of harmonics, which must be used for the mean and the variance, has to be repeatedly applied in order to evaluate the values $\hat{\lambda}$ of the parameter $\lambda$, which makes Gaussian the random variable $Z_{k}$ and, more specifically, minimizes the function expressed by the following equation:

$$
S_{G}^{2}(\lambda)=\frac{g_{1, Z}^{2}(\lambda)}{\sigma_{g_{1, z}}^{2}}+\frac{\left[g_{2, Z}(\lambda)-3\right]^{2}}{\sigma_{g_{2, z}}^{2}}
$$

where $g_{1, Z}$ and $g_{2, Z}$ are the sample skewness and kurtosis coefficients, evaluated on the basis of the $N_{K}$ observed values of $Z_{k}$, while $\sigma_{g_{1, z}}^{2}$ and $\sigma_{g_{2, z}}^{2}$ indicate their sample variances:

$$
\begin{gathered}
\sigma_{g_{1, z}}^{2}=6 N_{K}\left(N_{K}-1\right) /\left[\left(N_{K}-2\right)\left(N_{K}+1\right)\left(N_{K}+3\right)\right] \\
\sigma_{g_{2, z}}^{2}=24 N_{K}\left(N_{K}-1\right)^{2} /\left[\left(N_{K}-2\right)\left(N_{K}^{2}-9\right)\left(N_{K}+5\right)\right]
\end{gathered}
$$

The values of skewness, $g_{1, Z}(\hat{\lambda})$, and kurtosis, $g_{2, Z}(\hat{\lambda})$, can then be used to test the Gaussianity of the process of the $Z_{k}$. The Gaussianity hypothesis cannot be rejected if $g_{1, Z}(\hat{\lambda})$ and $g_{2, Z}(\hat{\lambda})$ fall within the intervals:

$$
\begin{gathered}
\left(-g_{1, Z ; 1-\alpha / 2}^{\left(N_{K}\right)} ; g_{1, Z ; 1-\alpha / 2}^{\left(N_{K}\right)}\right) \\
\left(g_{2, Z ; \alpha / 2}^{\left(N_{K}\right)} ; g_{2, Z ; 1-\alpha / 2}^{\left(N_{K}\right)}\right)
\end{gathered}
$$

where $g_{1, Z ; 1-\alpha / 2}^{\left(N_{K}\right)}$ is the percentile $1-\alpha / 2$ of the sample skewness distribution of the standardized Gaussian law with dimension $N_{K}$, while $g_{2, Z ; \alpha / 2}^{\left(N_{K}\right)}$ and $g_{2, Z ; 1-\alpha / 2}^{\left(N_{K}\right)}$ are the percentiles $\alpha / 2$ and $1-\alpha / 2$ of the sample kurtosis distribution of the standardized Gaussian law with dimension $N_{K}$.

The required percentiles can be evaluated through Monte Carlo simulation techniques after having analyzed the correlative features of the variable $Z_{k}$.

\section{Correlative Structure}

Usually, the sequence of random variables $Z_{k}$ with $k=1,2, \ldots$, shows a weak correlative structure which, if significant, can be modeled as an autoregressive process of order $p$. Being $Z_{k}$ standardized Gaussian variables, and given a white noise standardized Gaussian process $W_{k}$, then:

$$
Z_{k}=\psi_{0} W_{k}+\sum_{l=1}^{p} \phi_{l} Z_{k-l}
$$

Using the sample values $r_{Z, l}$ of the autocorrelation coefficients of lag $l=1, \ldots, p$ of the sequence $Z_{k}$, it is possible to obtain the estimations $\hat{\phi}_{l}$ of the parameters $\varphi_{1}$ by solving the Yule-Walker system, and to estimate $\psi_{0}$ as $\hat{\psi}_{0}=\sqrt{1-\sum_{l=1}^{p} \hat{\phi}_{l} r_{Z, l}}$ [97].

The $p$-order of the autoregressive process can be fixed as the minimum value for which cannot be rejected the hypothesis $H_{0, p}^{\left(\rho_{v}\right)}$ that the sample biases $w_{p, k}=\left(z_{k}-\sum_{l=1}^{p} \hat{\phi}_{l} z_{k-l}\right) / \hat{\psi}_{0}$, with $k=p+1$, $p+2$, are uncorrelated for lag $v=1,2, \ldots$ The hypothesis $H_{0, p}^{\left(\rho_{v}\right)}$ can be tested, at a significance level $\alpha$, by using the Anderson test $[98,99]$. The test must be applied also in the case $p=0$, for which $W_{0, k}=Z_{k}$ and $w_{0, k}=z_{k}$, in order to verify the hypothesis that the process $Z_{k}$ can be considered as white noise. 


\section{Case Study}

The study area (the region of Calabria) is a peninsula with an oblong shape occupying the southern part of Italy. It has a surface of $15,080 \mathrm{~km}^{2}$ and a coastline of $738 \mathrm{~km}$ on the Ionian and Tyrrhenian Seas. Calabria has a length of about $250 \mathrm{~km}$ and a width ranging between 31 and $111 \mathrm{~km}$. The maximum elevation is $2267 \mathrm{~m}$ a.s.l., while the average elevation is $597 \mathrm{~m}$ a.s.l. [100].

Because of its geographic position and mountainous nature, Calabria has a high climatic variability with a typically dry summer subtropical climate, also known as the Mediterranean climate [101]. Its coastal zones are characterized by mild winters and hot summers with little precipitation. In particular, the Ionian side, which is influenced by currents coming from Africa, has high temperatures with short and heavy precipitation, while the Tyrrhenian side is influenced by western air currents and presents milder temperatures and considerable orographic precipitation. In the inland zones there are colder winters (with snow) and fresher summers (with some precipitation) than those marking the coastal zones [102].

Monthly precipitation data have been collected and published in the region of Calabria by the former Italian Hydrographic Service. In this work, particular attention has been given to the problems arising from the low quality and inhomogeneities of the data series. Thus, the monthly database used in the further analysis was a part of the high-quality one presented in a previous study [103], in which a multiple application of the Craddock test [104] to detect the inhomogeneities was performed. In particular, in the present work, a set of 12 monthly total precipitation series, which were found to be homogeneous for the period 1916-2011, were selected. In Figure 1, the study area and the characterization of the rainfall series through box plots are presented. The main features of the rain gauges are shown in Table 2, together with the percentages of missing data. The percentage of gaps in the series ranges between 1.5 and $12.4 \%$, and is mostly detected during the Second World War period.

Table 2. Main features of the selected rain gauges.

\begin{tabular}{cccccccc}
\hline Code & Rain Gauge & $\begin{array}{c}\text { Longitude } \\
\text { (Degrees) }\end{array}$ & $\begin{array}{c}\text { Latitude } \\
\text { (Degrees) }\end{array}$ & $\begin{array}{c}\text { Elevation } \\
\text { (m a.s.l.) }\end{array}$ & $\begin{array}{c}\text { First } \\
\text { Year }\end{array}$ & $\begin{array}{c}\text { Last } \\
\text { Year }\end{array}$ & $\begin{array}{c}\text { Missing } \\
\text { Data (\%) }\end{array}$ \\
\hline 970 & Cassano allo Ionio & 16.319 & 39.783 & 250 & 1921 & 2011 & 10.4 \\
1010 & Cosenza & 16.265 & 39.287 & 242 & 1916 & 2011 & 3.5 \\
1030 & San Pietro in Guarano & 16.314 & 39.346 & 660 & 1922 & 2011 & 2.5 \\
1100 & Cecita ex Acquacalda & 16.538 & 39.400 & 1180 & 1923 & 2011 & 7.1 \\
1700 & Isola di Capo Rizzuto & 17.094 & 38.961 & 90 & 1922 & 2011 & 10.6 \\
2310 & Capo Spartivento & 16.056 & 37.927 & 48 & 1921 & 2011 & 12.4 \\
2510 & Scilla & 15.720 & 38.252 & 73 & 1939 & 2011 & 2.3 \\
2600 & Cittanova & 16.078 & 38.352 & 407 & 1916 & 2011 & 11.5 \\
2760 & Joppolo & 15.905 & 38.592 & 185 & 1929 & 2011 & 2.3 \\
2830 & Filadelfia & 16.293 & 38.787 & 550 & 1920 & 2011 & 3.3 \\
2890 & Tiriolo & 16.510 & 38.940 & 690 & 1941 & 2011 & 2.9 \\
3160 & Campotenese C.C. & 16.068 & 39.873 & 965 & 1922 & 2011 & 1.5 \\
\hline
\end{tabular}




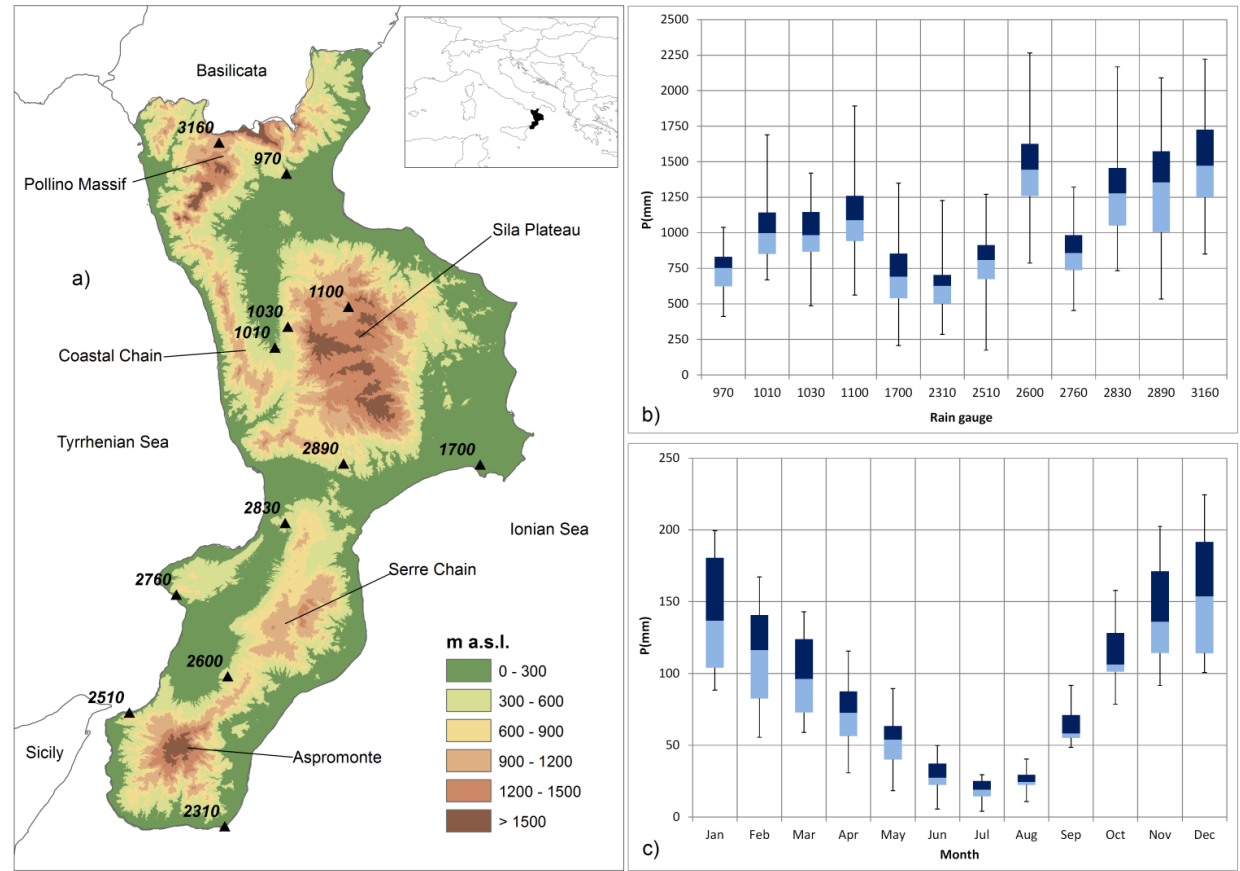

Figure 1. Localization of the selected rain gauges on a DEM of the region of Calabria (a) and characterization of the rainfall series through box plots: (b) annual rainfall for each rain gauge; (c) monthly rainfall distribution for the whole set of rain gauges. The bottom and top of the box are the first and third quartiles, the band inside the box is the median, the ends of the whiskers represent the minimum and maximum of all of the data.

\section{Estimation of the Model Parameters}

All the monthly total rainfall series present some months with no data. For this reason, the estimation of the truncated Fourier coefficients for mean and variance functions have been made, as mentioned in Section 2.2, with the use of the least squares method by solving systems of linear algebraic equations, assuming $I_{0}=1 \mathrm{~mm}$. Instead, in the procedure for the evaluation of the parameter $\lambda$, the minimum of the function in Equation (6) has been evaluated by applying the Brent algorithm, which was preceded by the search of a bracketing interval for the minimum [105].

For the 12 rain gauges selected in this work, Tables 3 and 4 report the estimated values of $\hat{\lambda}$, of the number of harmonics $N_{h}^{(\mu)}$ and $N_{h}^{\left(\sigma^{2}\right)}$, and of the Fourier coefficients. As to what concerns the mean function (Table 3), 2 harmonics have been evaluated for all the rain gauges with the exception of the Capo Spartivento rain gauge, for which 3 harmonics are needed.

Table 3. Coefficient $\hat{\lambda}$ and Fourier coefficients for the mean function $\tilde{\mu}_{Y, j}$.

\begin{tabular}{cccccccccc}
\hline Rain Gauge & $\hat{\lambda}$ & $N_{h}^{(\mu)}$ & $\hat{a}_{0}^{(\mu)} / 2$ & $\hat{a}_{1}^{(\mu)}$ & $\hat{b}_{1}^{(\mu)}$ & $\hat{a}_{2}^{(\mu)}$ & $b_{2}^{(\mu)}$ & $\hat{a}_{3}^{(\mu)}$ & $b_{3}^{(\mu)}$ \\
\hline Campotenese & 0.466 & 2 & 1.730 & 0.649 & 0.265 & 0.009 & -0.203 & - & - \\
Capo Spartivento & 0.338 & 3 & 0.962 & 0.504 & 0.089 & -0.080 & -0.151 & -0.021 & 0.050 \\
Cassano allo Jonio & 0.473 & 2 & 1.256 & 0.473 & 0.158 & -0.022 & -0.121 & - & - \\
Cecita & 0.442 & 2 & 1.448 & 0.543 & 0.251 & 0.011 & -0.129 & - & - \\
Cittanova & 0.401 & 2 & 1.551 & 0.587 & 0.246 & -0.026 & -0.199 & - & - \\
Cosenza & 0.477 & 2 & 1.429 & 0.637 & 0.248 & 0.005 & -0.183 & - & - \\
Filadelfia & 0.477 & 2 & 1.626 & 0.675 & 0.274 & 0.027 & -0.184 & - & - \\
Isola Capo Rizzuto & 0.315 & 2 & 1.000 & 0.450 & 0.135 & -0.020 & -0.167 & - & - \\
Joppolo & 0.498 & 2 & 1.361 & 0.620 & 0.169 & -0.006 & -0.196 & - & - \\
S.Pietro in Guarano & 0.513 & 2 & 1.480 & 0.692 & 0.278 & 0.011 & -0.214 & - & - \\
Scilla & 0.484 & 2 & 1.295 & 0.553 & 0.090 & -0.080 & -0.175 & - & - \\
Tiriolo & 0.405 & 2 & 1.451 & 0.591 & 0.210 & -0.019 & -0.138 & - & - \\
\hline
\end{tabular}


Table 4. Fourier coefficients for the variance function.

\begin{tabular}{ccccccccc}
\hline Rain Gauge & $N_{h}^{\left(\sigma^{2}\right)}$ & $a_{0}^{\left(\sigma^{2}\right)} / 2$ & $\hat{a}_{1}^{\left(\sigma^{2}\right)}$ & $\hat{b}_{1}^{\left(\sigma^{2}\right)}$ & $\hat{a}_{2}^{\left(\sigma^{2}\right)}$ & $\hat{b}_{2}^{\left(\sigma^{2}\right)}$ & $\hat{a}_{2}^{\left(\sigma^{2}\right)}$ & $\hat{b}_{2}^{\left(\sigma^{2}\right)}$ \\
\hline Campotenese & 2 & 0.345 & 0.112 & 0.020 & 0.010 & 0.048 & - & - \\
Capo Spartivento & 2 & 0.140 & 0.024 & -0.036 & -0.029 & -0.017 & - & - \\
Cassano allo Jonio & 2 & 0.205 & 0.039 & -0.010 & 0.003 & 0.041 & - & - \\
Cecita & 2 & 0.232 & 0.051 & -0.002 & 0.019 & 0.015 & - & - \\
Cittanova & 1 & 0.224 & 0.005 & -0.026 & - & - & - & - \\
Cosenza & 2 & 0.259 & 0.082 & 0.024 & -0.007 & 0.051 & - & - \\
Filadelfia & 3 & 0.353 & 0.024 & 0.008 & 0.037 & 0.022 & -0.058 & 0.005 \\
Isola Capo Rizzuto & 3 & 0.157 & 0.014 & -0.062 & -0.035 & 0.006 & -0.017 & -0.001 \\
Joppolo & 1 & 0.282 & 0.033 & -0.004 & - & - & - & - \\
S.Pietro in Guarano & 2 & 0.310 & 0.094 & 0.032 & -0.006 & 0.031 & - & - \\
Scilla & 1 & 0.241 & 0.015 & -0.017 & - & - & - & - \\
Tiriolo & 2 & 0.236 & 0.045 & 0.021 & -0.010 & 0.029 & - & -
\end{tabular}

Different results have been obtained for the variance function (Table 4). In fact, 1 harmonic has been evaluated for 3 out of 12 rain gauges, 2 harmonics for 7 rain gauges, and 3 harmonics for the other 2 rain gauges. Moreover, the comparisons among the observed values, $m_{Y, j}$ and $s_{Y, j^{\prime}}^{2}$, the modeled values, $\widetilde{\mu}_{Y, j}$ and $\widetilde{\sigma}_{Y, j}^{2}$, and the dimension of the non-rejection intervals of the hypotheses $H_{0}^{(\mu)}$ and $H_{0}^{\left(\sigma^{2}\right)}$ are shown in Figure 2 for the Cosenza and Campotenese C.C. rain gauges.
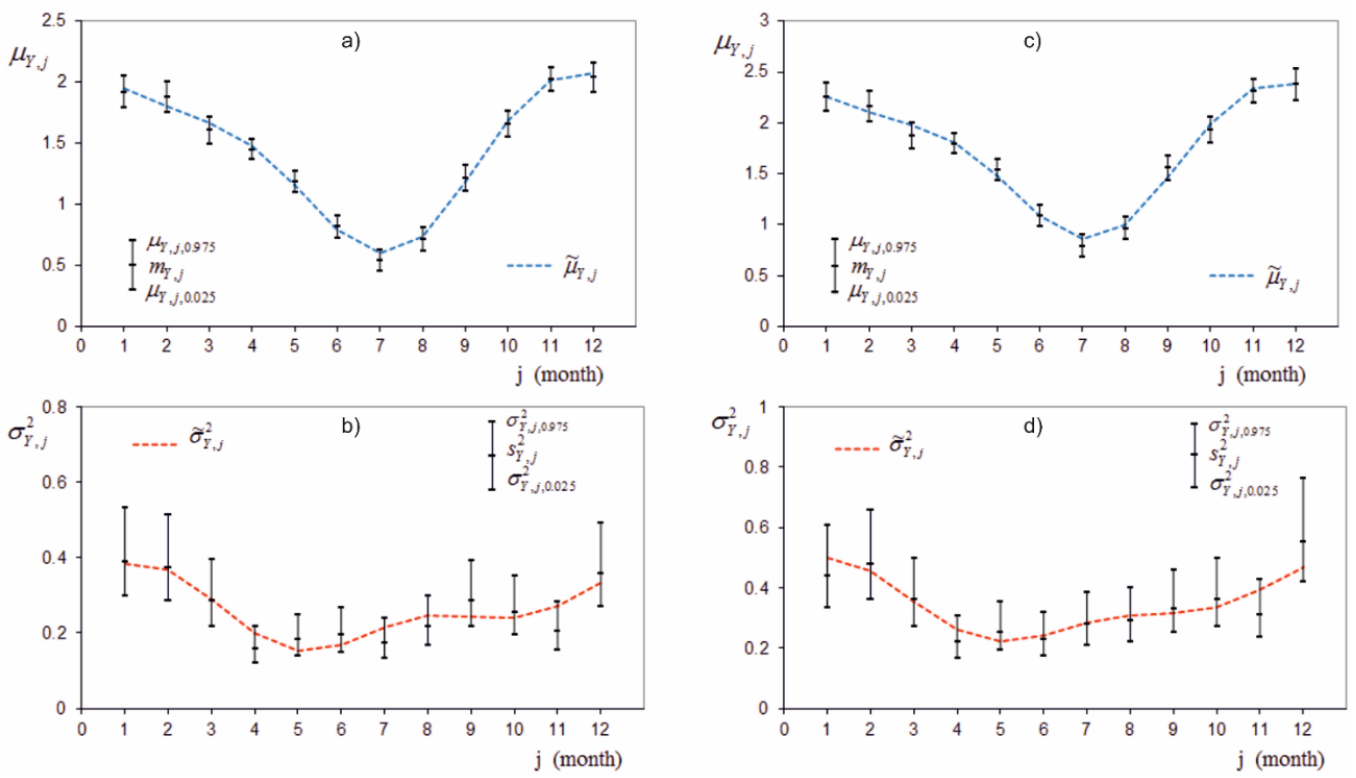

Figure 2. Comparison among the observed values, the modeled values, and the ranges (identified by the whiskers of the error bar) of the non-rejection regions of the hypotheses $H_{0}^{(\mu)}$ and $H_{0}^{\left(\sigma^{2}\right)}$, for the mean (blue) and the variance (red) functions, evaluated for the Cosenza (a,b) and the Campotenese C.C. $(\mathbf{c}, \mathbf{d})$ rain gauges.

By using the estimated values of the parameters, and by means of Equation (2), it was possible to build the observed sample $z_{k}$, with zero mean and unit variance, and the sample coefficients of skewness, $g_{1, Z}$, and kurtosis, $g_{2, Z}$. These values have been used to test the Gaussianity of the process $Z_{k}$, by verifying the non-rejection of the hypotheses $H_{0}^{\left(g_{1}\right)}$ and $H_{0}^{\left(g_{2}\right)}$ (Table 5). Moreover, the comparisons between the cumulative frequency of the observed values and the cumulative distribution function (cdf) of the standardized Gaussian law have been reported in Figure 3, for the Cecita ex Acquacalda and Scilla rain gauges. The non-rejection of the hypotheses $H_{0}^{\left(g_{1}\right)}$ and $H_{0}^{\left(g_{2}\right)}$ and the good fitting with the observed values (Figure 3) confirm the goodness of the Gaussianization of the $Z_{k}$ process. 
Table 5. Gaussianity test based on the coefficients of skewness and kurtosis.

\begin{tabular}{ccccccc}
\hline Rain Gauge & $N_{K}$ & $g_{1, Z}$ & $\pm g_{1, Z ; 0.975}^{\left(N_{K}\right)}$ & $g_{2, Z ; 0.025}^{\left(N_{K}\right)}$ & $g_{2, Z}$ & $g_{2, Z ; 0.975}^{\left(N_{K}\right)}$ \\
\hline Campotenese & 1055 & -0.006 & \pm 0.148 & 2.731 & 2.813 & 3.315 \\
Capo Spartivento & 957 & -0.005 & \pm 0.155 & 2.718 & 2.857 & 3.333 \\
Cassano allo Jonio & 969 & -0.005 & \pm 0.154 & 2.720 & 2.746 & 3.331 \\
Cecita & 985 & 0.012 & \pm 0.153 & 2.722 & 3.114 & 3.328 \\
Cittanova & 1020 & -0.001 & \pm 0.151 & 2.726 & 3.164 & 3.321 \\
Cosenza & 1112 & -0.028 & \pm 0.144 & 2.738 & 2.814 & 3.304 \\
Filadelfia & 1067 & -0.001 & \pm 0.147 & 2.732 & 2.994 & 3.313 \\
Isola Capo Rizzuto & 962 & -0.013 & \pm 0.155 & 2.719 & 2.828 & 3.332 \\
Joppolo & 968 & 0.008 & \pm 0.154 & 2.720 & 3.184 & 3.331 \\
S.Pietro in Guarano & 1047 & 0.005 & \pm 0.149 & 2.730 & 3.046 & 3.316 \\
Scilla & 857 & 0.000 & \pm 0.162 & 2.706 & 2.951 & 3.352 \\
Tiriolo & 827 & 0.001 & \pm 0.165 & 2.702 & 3.021 & 3.357 \\
\hline
\end{tabular}

For all the rain gauges, the sequences of observed values $z_{k}$ show low linear correlation coefficients, but they are not low enough to consider the process $Z_{k}$ uncorrelated. In fact, the application of the Anderson test, with a lag $v_{\max }=24$, to the $z_{k}$ series, evidenced that the hypothesis of uncorrelated process is non-rejectable only for the Cassano allo Jonio, Capo Spartivento and Joppolo rain gauges.

For the other 9 rainfall series, in order to describe the correlative structure, it was sufficient to adopt an autoregressive model of order $p=1$. In fact, after the estimation of the parameters $\hat{\phi}_{1}=r_{1, z}$ and $\hat{\psi}_{0}=\sqrt{1-r_{1, Z}^{2}}$, the application of the Anderson test, always till a lag $v_{\max }=24$, to the sequence of the sample bias $w_{1, k}$, showed the non-rejectability of the hypothesis of uncorrelated process. Table 6 shows a synthesis of the application of the Anderson test to the selected 12 rain gauges, limited only to the lag $v=1$.

Table 6. Anderson test applied to the autocorrelation coefficient of lag $v=1$.

\begin{tabular}{|c|c|c|c|c|c|c|c|c|}
\hline Rain Gauge & $r_{Z, 1 ; 0.025}^{\left(N_{K, 0}\right)}$ & $r_{Z, 1}$ & $r_{Z, 1 ; 0.975}^{\left(N_{K, 0}\right)}$ & $H_{0,0}^{\left(\rho_{1}\right)}$ & $r_{W_{1}, 1 ; 0.025}^{\left(N_{K, 1}\right)}$ & $r_{W_{1}, 1}$ & $r_{W_{1}, 1 ; 0.975}^{\left(N_{K}\right)}$ & $H_{0,1}^{\left(\rho_{1}\right)}$ \\
\hline Campotenese & -0.062 & 0.070 & 0.060 & rejected & -0.062 & -0.004 & 0.060 & not rejected \\
\hline Capo Spartivento & -0.065 & 0.005 & 0.063 & not rejected & - & - & - & - \\
\hline Cassano allo Jonio & -0.065 & 0.042 & 0.063 & not rejected & - & - & - & - \\
\hline Cecita & -0.064 & 0.067 & 0.062 & rejected & -0.064 & 0.003 & 0.062 & not rejected \\
\hline Cittanova & -0.063 & 0.113 & 0.061 & rejected & -0.063 & -0.004 & 0.061 & not rejected \\
\hline Cosenza & -0.060 & 0.065 & 0.058 & rejected & -0.060 & 0.004 & 0.058 & not rejected \\
\hline Filadelfia & -0.062 & 0.117 & 0.060 & rejected & -0.062 & -0.008 & 0.060 & not rejected \\
\hline Isola Capo Rizzuto & -0.065 & 0.073 & 0.063 & rejected & -0.065 & 0.007 & 0.063 & not rejected \\
\hline Joppolo & -0.064 & 0.061 & 0.062 & not rejected & - & - & - & - \\
\hline S.Pietro in Guarano & -0.062 & 0.097 & 0.060 & rejected & -0.062 & -0.011 & 0.060 & not rejected \\
\hline Scilla & -0.069 & 0.154 & 0.066 & rejected & -0.069 & -0.017 & 0.066 & not rejected \\
\hline Tiriolo & -0.070 & 0.103 & 0.068 & rejected & -0.070 & -0.013 & 0.068 & not rejected \\
\hline
\end{tabular}



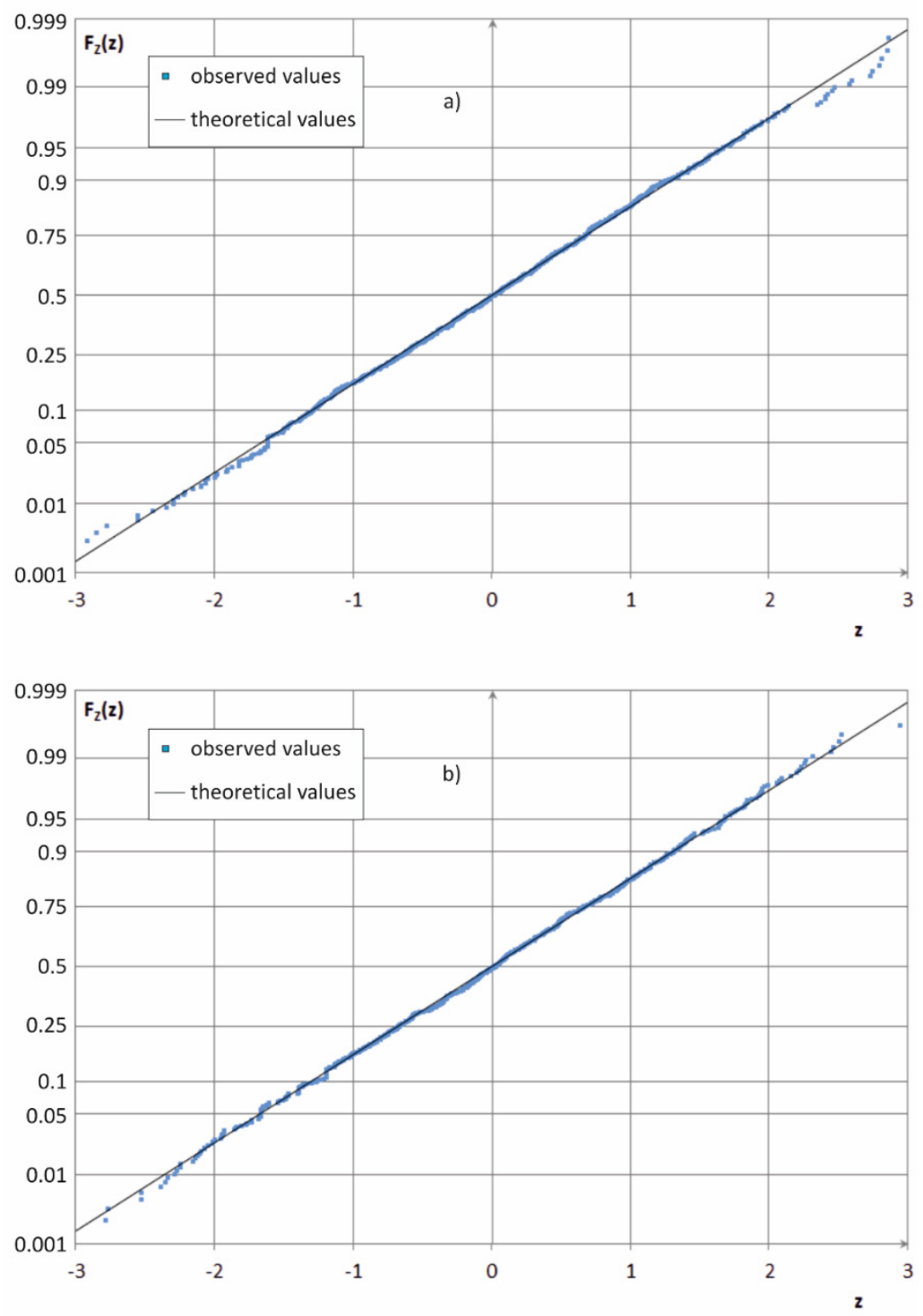

Figure 3. Comparison between the cumulative frequency of the observed values and the cdf of the standardized Gaussian law for the Cecita ex Acquacalda (a) and Scilla (b) rain gauges.

\section{Results and Discussion}

After the parameter estimation by means of the selected rainfall database, $10^{4}$ years long synthetic series have been generated for each rain gauge through a Monte Carlo procedure, reproducing the proposed model.

Then, the SPI was evaluated at two different time scales: 3-month SPI, which reflects short- and medium-term moisture conditions, and 12-month SPI, which is linked to long-term precipitation patterns and can impact on streamflows, reservoir levels, and even groundwater levels. The results obtained in terms of the occurrence probabilities of wet and dry conditions were compared with the class probability shown in Table 1.

In Figure 4, the results of the 12-month SPI for two rain gauges are shown (Isola di Capo Rizzuto and Capo Spartivento). 


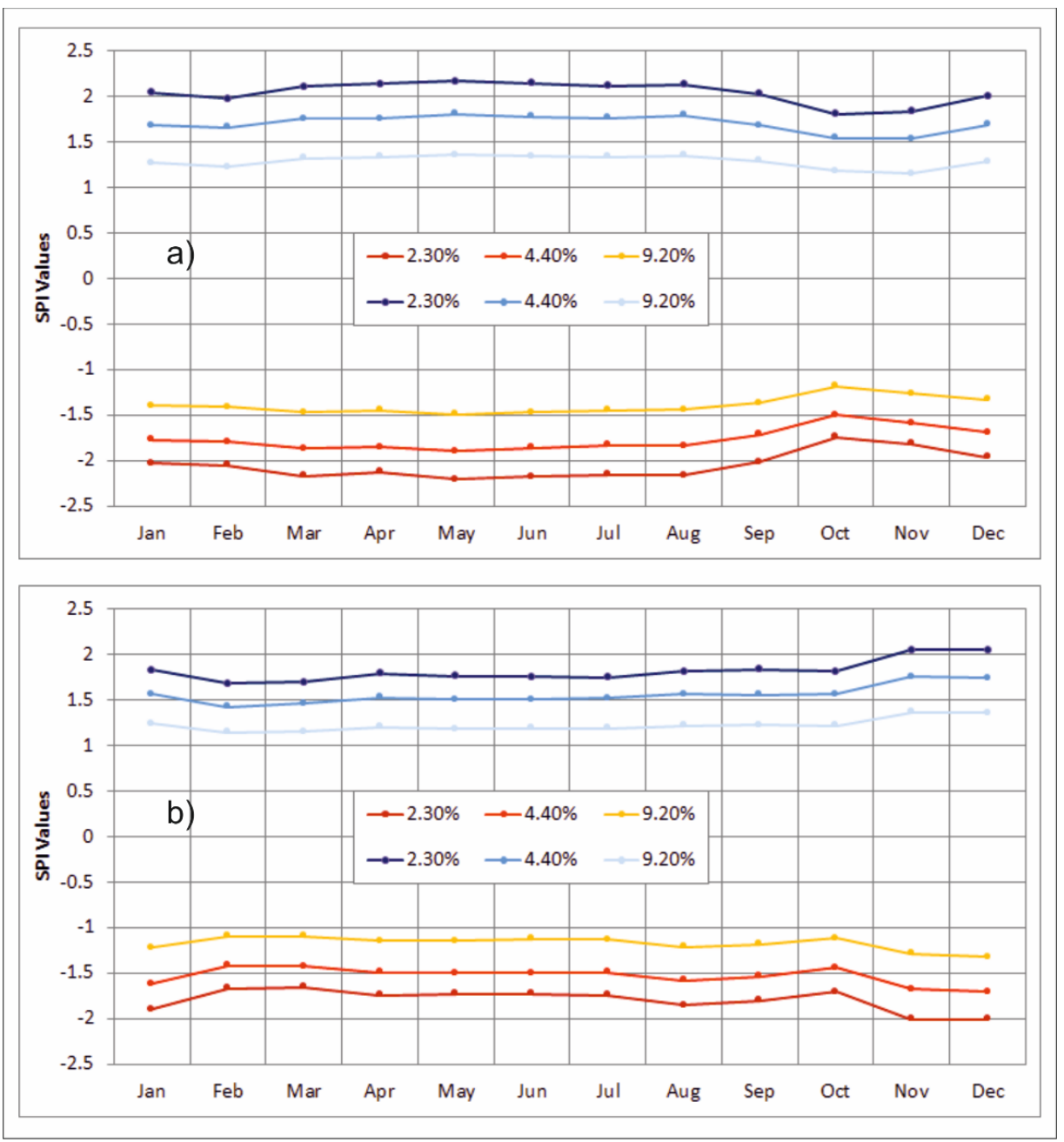

Figure 4. Values of the 12-month SPI for fixed monthly occurrence probabilities of wet and dry conditions, evaluated for the simulated data of the Isola di Capo Rizzuto (a) and the Capo Spartivento (b) rain gauges. According to the theoretical values proposed in another publication [86], each color identifies the prefixed value of the occurrence probability of wet (blue scale) and dry (red scale) conditions.

In this figure, by means of the simulated data, the SPI values corresponding to the probability of extreme $(2.3 \%)$, severe $(4.4 \%)$ and moderate $(9.2 \%)$ conditions have been detected for each month. As a result, the probabilities proposed in another publication [86] in the evaluation of the SPI were quite different from the ones obtained by the application of the SPI to the $10^{4}$ simulated years. For example, for the Isola di Capo Rizzuto rain gauge (Figure 4a), the occurrence probabilities of the extreme values confirmed the correspondent SPI values previously proposed [86], while the severe and moderate probabilities values showed a different behavior. Similarly, for the Capo Spartivento rain gauge (Figure $4 \mathrm{~b}$ ), the extreme and moderate probabilities differed from the correspondent SPI values proposed in Table 1, while only the severe probabilities agree with them. This is very important, since for most practical applications the SPI is essential in terms of classification (Table 1) and not as arithmetic values [87].

As regards to the 3-month-SPI, Figure 5 presents some box plots that summarized the regional monthly occurrence probabilities of the different wet and dry classes. In particular, the box plots corresponding to extreme, severe and moderate dry and wet conditions have been shown together with the theoretical values proposed by [86]. From these analyses it has emerged that in Calabria, as in other Italian regions [43], the highest probability to detect extreme drought (Figure 5a) or severe 
drought (Figure 5b) conditions, were mainly observed in the wet seasons and, in particular, in the autumn period. In fact, the autumn and the spring months showed the highest values of the mean occurrence probabilities of drought, while the minimum values have been detected in August.

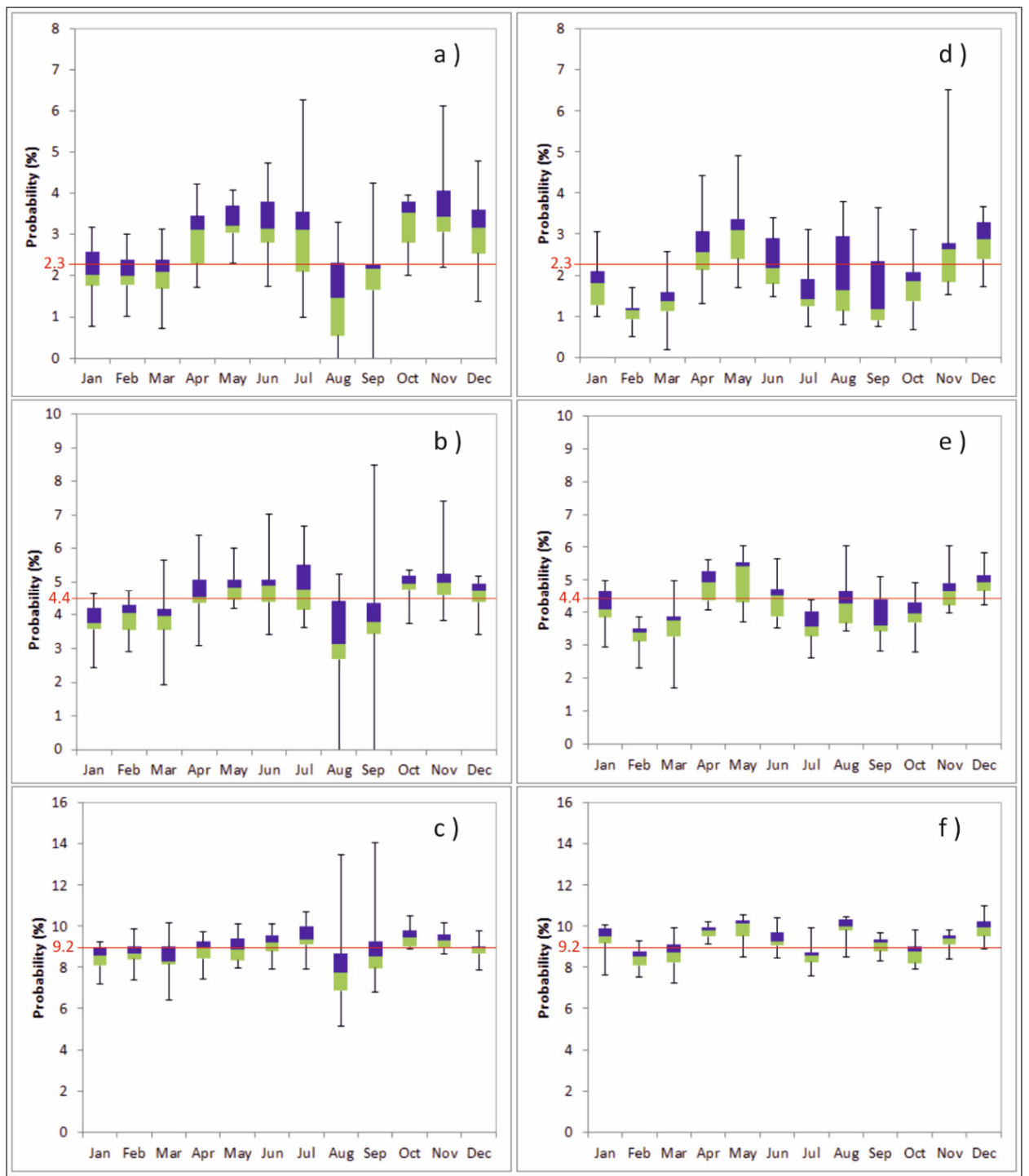

Figure 5. Box-plots of the regional monthly occurrence probabilities of extreme drought (a); severe drought (b); moderate drought (c); extremely wet (d), severely wet (e) and moderately wet (f) conditions for the 3-month SPI. The red lines indicate the theoretical values proposed by [86]. The bottom and top of the box are the first and third quartiles, the band inside the box is the median, the ends of the whiskers represent the minimum and maximum of all of the data.

Moreover, in the summer period, the occurrence probabilities of drought conditions showed a high regional variability, with large difference values between the several rain gauges. Conversely, the highest probability to detect extremely wet (Figure 5d) or severely wet (Figure 5e) conditions, were mainly observed in winter. No remarkable differences emerged for the moderate dry (Figure $5 \mathrm{c}$ ) and wet (Figure 5f) conditions.

With regards to the comparison between the occurrence probabilities of wet and dry conditions evaluated from the simulated data and the class probability shown in Table 1, the different dry and wet mean occurrence values generally fluctuate around the values proposed by [86], but higher probability of extreme drought (Figure 5a) can be observed. 
Similarly to Figure 5, also for the 12-month SPI, the box plots with the regional monthly occurrence probabilities of the different wet and dry classes have been evaluated (Figure 6). As opposed to Figure 5, in these box plots there are few differences between the occurrence probabilities evaluated in the different months, in particular for the dry conditions. In fact, highest probabilities to detect extreme drought (Figure 6a) or severe drought (Figure 6b) conditions can be observed in the summer period. Moreover, only for the extreme drought (Figure 6a) and in the summer period, the occurrence probabilities of drought conditions showed a high regional variability. The most important result of the 12-month SPI analysis emerged from the comparison between the occurrence probabilities of wet and dry conditions evaluated from the simulated data and the class probability shown in Table 1. In fact, the extreme (Figure 6a) and the severe drought (Figure 6b) mean occurrences values generally fluctuate around the values proposed by [86], and the moderate drought (Figure 6c) presented slightly higher mean occurrences values than these. By contrast, the wet conditions (Figure 6d-f) always showed lower mean occurrences values than those presented in Table 1.

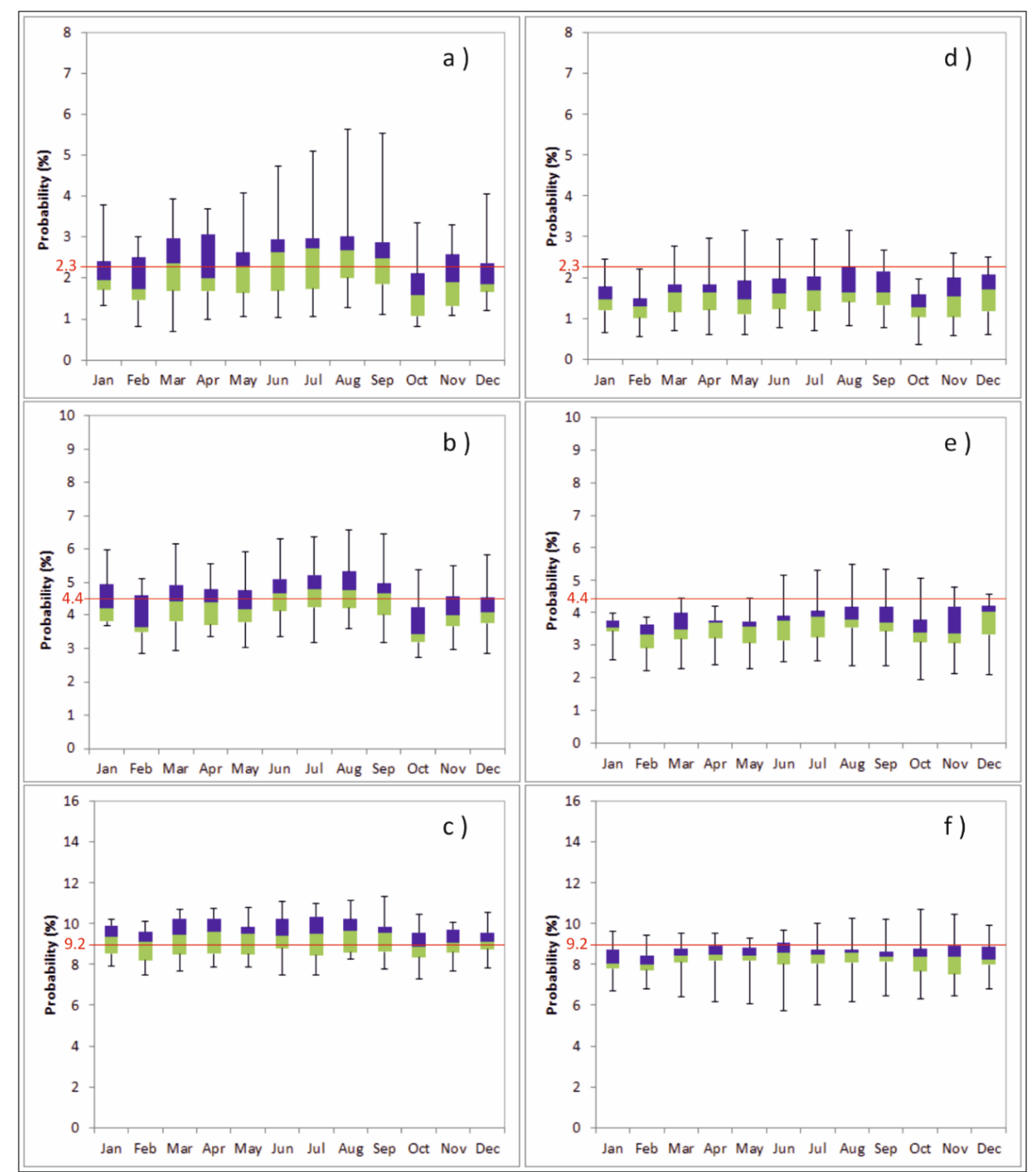

Figure 6. Box-plots of the regional monthly occurrence probabilities of extreme drought (a); severe drought (b); moderate drought (c), extremely wet (d); severely wet (e) and moderately wet (f) conditions for the 12-month SPI. The red lines indicate the theoretical values proposed by [86]. The bottom and top of the box are the first and third quartiles, the band inside the box is the median, the ends of the whiskers represent the minimum and maximum of all of the data. 
These results indicate greater probability of dry conditions than wet conditions when long-term precipitation patterns are considered, with consequences on streamflows, reservoir levels, and groundwater levels.

Generally, from the box plots of Figures 5 and 6 it can be observed that the 3-month SPI does not greatly vary in comparison to the 12-month SPI. The only exception are the box plots which refer to the extreme wet conditions (Figures $5 \mathrm{~d}$ and $6 \mathrm{~d}$ ) where, in 10 out of 12 months, the probability of the 3-month SPI evidenced a greater spread than the 12-month SPI. These results agree with the ones shown in Figure 7 and with past studies in the region of Calabria [41,42], which evidenced that there is a great spatial heterogeneity of the SPI12 while the SPI3 shows a spatial homogeneity. Moreover, as a further result, the model spreads higher in summer than in the other seasons. This result can be due to the Mediterranean climate of the region, which shows high climatic variability with a typically dry summer subtropical climate. The rain gauges with the higher spread in summer are located in the Ionian side of the region, which is influenced by currents coming from Africa and is characterized by short and heavy precipitation in particular in the summer period.
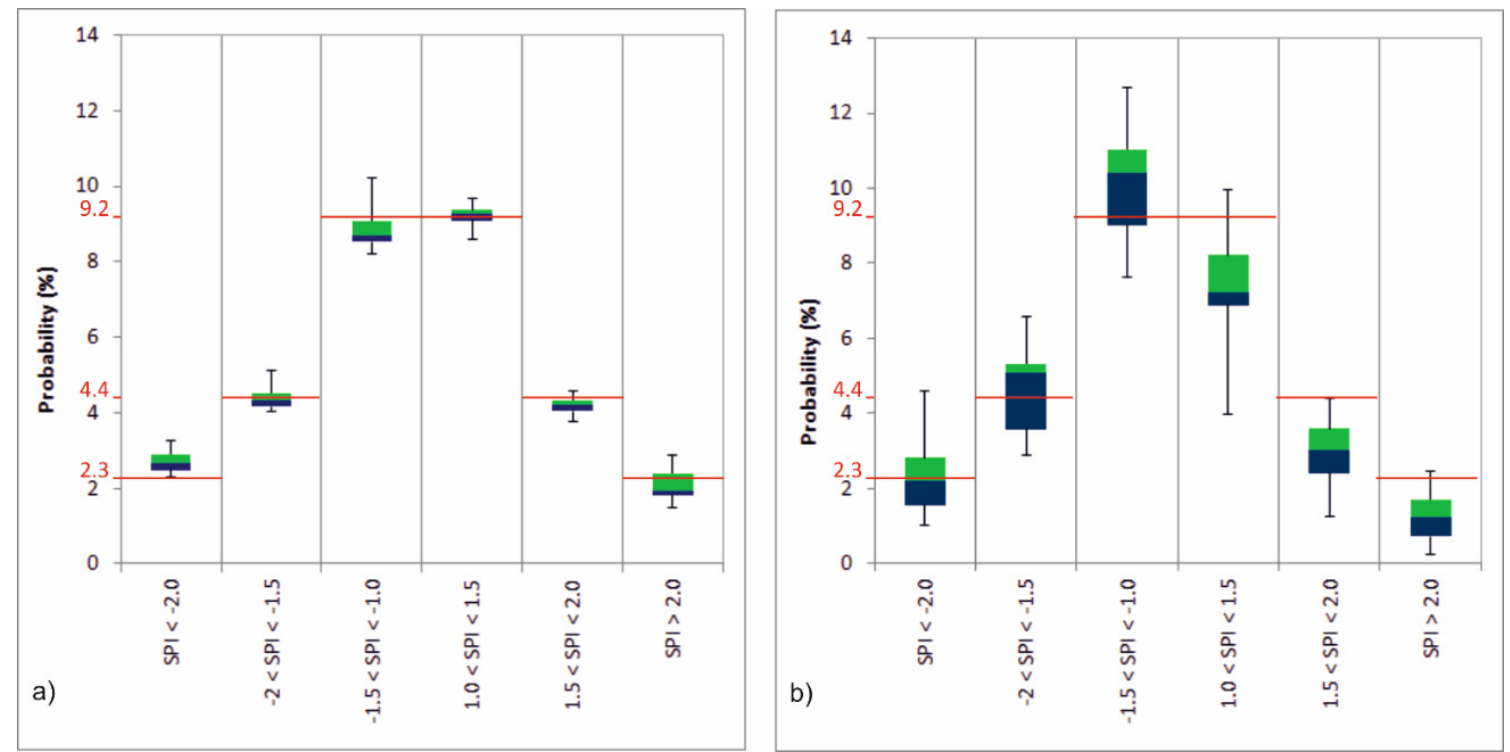

Figure 7. Box-plots of the regional occurrence probabilities of extreme, severe and moderate drought and wet conditions for the 3-month SPI (left) and the 12-month SPI (right). The lines indicate the theoretical values proposed by [86]. The bottom and top of the box are the first and third quartiles, the band inside the box is the median, the ends of the whiskers represent the minimum and maximum of all of the data.

Figure 7 shows the box plots with the occurrence probabilities of the different wet and dry classes evaluated for the whole data series.

In particular, for the 3-month SPI (Figure 7a), there are no marked differences between the evaluated mean occurrences probabilities and the ones previously proposed [86], and the same happens between the occurrence probability of the corresponding dry/wet classes. Instead, for the 12-month SPI (Figure 7b) strong differences between the evaluated mean occurrences probabilities and the ones shown in Table 1 have been detected, with the drought and wet conditions which present respectively higher and lower values than the ones previously proposed [86].

Detailed results for each rain gauge have been shown in Table 7. The results confirm more chance for dry conditions than wet conditions when long-term precipitation patterns are considered. In fact, for almost all the rain gauges, the lowest probability values have been detected for the wet conditions, while the highest probability values have been detected for the dry conditions. For example, for the Cosenza rain gauge (code 1010), the probabilities that the 12-month SPI belong to the extreme classes 
(SPI $<-2$ and SPI $>2$ ) are $4.2 \%$ and $2.0 \%$, respectively. The same happens for the severe SPI classes $(-2<\mathrm{SPI}<-1.5$ and $1.5<\mathrm{SPI}<2)$ where dry conditions show higher probabilities $(5.9 \%)$ than wet conditions (4.0\%). A similar behavior is shown by the 3-month SPI, even though with lower marked differences between dry and wet conditions (Table 7). These results, which evidence the highest probability values evaluated for the dry conditions, are visually described in Figure 8 . The different colors of the figure represent several probability classes. In fact, the colors associated to the ranges with higher probabilities can be observed only for dry conditions. On the contrary, the lower probability classes can be identified mainly for the wet conditions.

Table 7. Probability of the simulated data to fall within each SPI class evaluated for each rain gauge.

\begin{tabular}{cccccccccccccc}
\hline Months & SPI Class & $\mathbf{9 7 0}$ & $\mathbf{1 0 1 0}$ & $\mathbf{1 0 3 0}$ & $\mathbf{1 1 0 0}$ & $\mathbf{1 7 0 0}$ & $\mathbf{2 3 1 0}$ & $\mathbf{2 5 1 0}$ & $\mathbf{2 6 0 0}$ & $\mathbf{2 7 6 0}$ & $\mathbf{2 8 3 0}$ & $\mathbf{2 8 9 0}$ & $\mathbf{3 1 6 0}$ \\
\hline & SPI $<-2$ & 2.6 & 3.0 & 3.3 & 2.9 & 2.3 & 2.7 & 2.5 & 2.7 & 2.3 & 2.3 & 2.9 & 2.6 \\
& $-2<$ SPI $<-1.5$ & 4.2 & 4.3 & 5.1 & 4.5 & 4.1 & 4.6 & 4.0 & 4.2 & 4.0 & 4.9 & 4.5 & 4.4 \\
3 & $-1.5<$ SPI $<-1$ & 8.4 & 8.7 & 9.1 & 9.1 & 10.2 & 9.2 & 8.5 & 8.6 & 8.2 & 8.8 & 9.1 & 8.5 \\
& $1<$ SPI $<1.5$ & 9.4 & 9.3 & 9.5 & 9.0 & 8.6 & 9.1 & 9.2 & 9.4 & 9.3 & 9.7 & 9.0 & 9.3 \\
& $1.5<$ SPI $<2$ & 4.2 & 4.3 & 4.6 & 4.0 & 4.3 & 4.3 & 4.0 & 4.3 & 3.8 & 4.6 & 4.0 & 4.1 \\
& SPI $>2$ & 1.7 & 1.9 & 2.4 & 1.9 & 2.7 & 2.9 & 1.5 & 2.4 & 1.5 & 2.4 & 2.0 & 1.8 \\
\hline & SPI $<-2$ & 1.7 & 4.2 & 3.1 & 2.4 & 2.7 & 1.7 & 2.2 & 1.3 & 2.4 & 2.2 & 1.9 & 1.3 \\
& $-2<$ SPI $<-1.5$ & 3.6 & 5.9 & 5.1 & 4.7 & 4.9 & 4.1 & 4.2 & 3.5 & 4.3 & 4.0 & 4.4 & 3.5 \\
12 & $-1.5<$ SPI $<-1$ & 8.5 & 10.6 & 9.8 & 9.9 & 10.1 & 9.3 & 9.2 & 8.0 & 9.1 & 8.0 & 10.1 & 8.5 \\
& $1<$ SPI $<1.5$ & 8.8 & 8.3 & 8.5 & 8.0 & 8.0 & 8.2 & 8.2 & 8.9 & 9.0 & 9.9 & 6.4 & 7.7 \\
& $1.5<$ SPI $<2$ & 3.5 & 4.0 & 3.9 & 3.3 & 3.8 & 3.8 & 3.3 & 3.5 & 3.8 & 4.7 & 2.3 & 2.7 \\
& SPI $>2$ & 1.2 & 2.0 & 1.6 & 1.4 & 2.5 & 1.9 & 1.2 & 1.5 & 1.7 & 2.1 & 0.7 & 0.9 \\
\hline
\end{tabular}

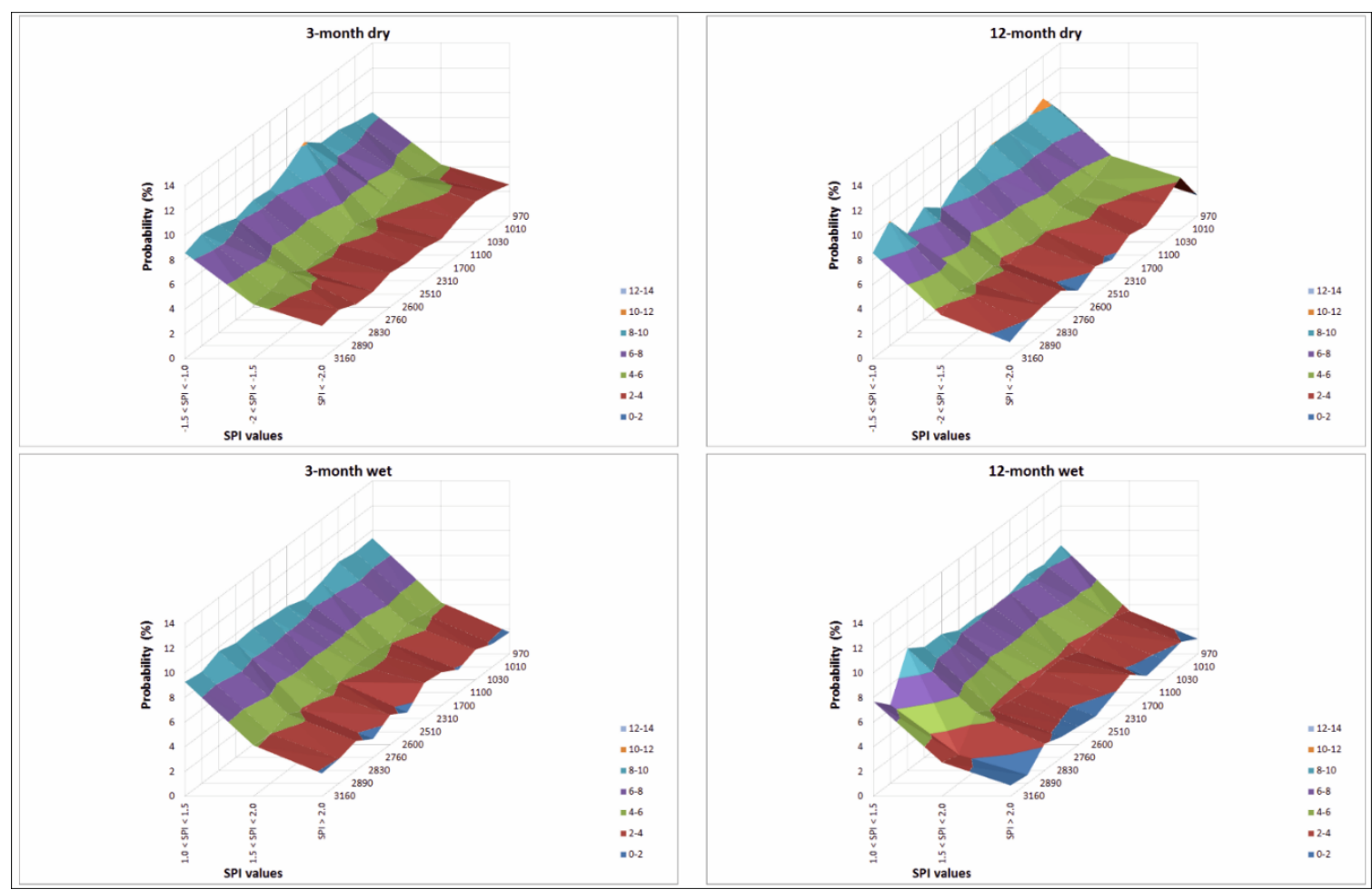

Figure 8. Occurrence probabilities of extreme, severe and moderate drought and wet conditions for the 3-month SPI and the 12-month SPI for each rain gauge.

Some results obtained from the application of the SPI are confirmed by the DSI, evaluated for each rain gauge on two time scales ( 3 and 6 months) using the synthetic monthly precipitation series. Table 8 compares the two indices (DSI3 and DSI6) at each location, in terms of percentages of months for which the drought severity index was negative, positive or equal to zero (no rainfall deficit). As 
was the case in a previous publication [25], for all the rain gauges a six-monthly rule (DSI6) hinders the development of a drought sequence. In fact, the deficit emerges considering rainfall behavior over three, rather than six months with a maximum percentage decrease of $9 \%$ (ID 1700) passing from DSI3 to DSI6. The different results obtained with DSI6 also appear when DSI values equal to zero are considered. For DSI3 the percentages of months with positive values are always greater than those equal to zero. On the contrary, for DSI6 there are rain gauges for which months with DSI equal to zero are greater than those with positive values. Some of the DSI features confirm the results of SPI. For example, the probabilities of extreme drought for SPI on large scale (in this study, 12 month-SPI) are often lower than those relative to 3-month SPI. Moreover, some of the rain gauges with the highest probabilities of extreme drought are the same, showing high percentages with positive values of DSI3 (i.e., ID 1030, 2310, 2600, 2890, 3160).

Table 8. Percentages of the simulated monthly data to fall within each DSI class evaluated for each rain gauge.

\begin{tabular}{lcllllllllllll}
\hline DSI & DSI Class & $\mathbf{9 7 0}$ & $\mathbf{1 0 1 0}$ & $\mathbf{1 0 3 0}$ & $\mathbf{1 1 0 0}$ & $\mathbf{1 7 0 0}$ & $\mathbf{2 3 1 0}$ & $\mathbf{2 5 1 0}$ & $\mathbf{2 6 0 0}$ & $\mathbf{2 7 6 0}$ & $\mathbf{2 8 3 0}$ & $\mathbf{2 8 9 0}$ & $\mathbf{3 1 6 0}$ \\
\hline \multirow{4}{*}{ DSI3 } & Negative & 0.5 & 0.4 & 0.4 & 0.5 & 0.5 & 0.5 & 0.3 & 0.4 & 0.4 & 0.4 & 0.3 & 0.3 \\
& Positive & 56.1 & 53.5 & 57.0 & 50.5 & 55.9 & 59.5 & 58.9 & 63.1 & 56.0 & 55.6 & 62.5 & 65.2 \\
& Zero & 43.4 & 46.0 & 42.6 & 49.0 & 43.6 & 40.0 & 40.7 & 36.6 & 43.6 & 44.0 & 37.1 & 34.5 \\
\hline \multirow{4}{*}{ DSI6 } & Negative & 0.9 & 1.0 & 0.9 & 0.9 & 0.9 & 0.8 & 0.8 & 0.8 & 0.9 & 0.9 & 0.8 & 0.7 \\
& Positive & 52.0 & 48.3 & 52.7 & 43.5 & 46.9 & 54.5 & 55.0 & 59.3 & 50.5 & 49.3 & 59.7 & 64.0 \\
& Zero & 47.1 & 50.7 & 46.4 & 55.6 & 52.3 & 44.7 & 44.2 & 39.9 & 48.6 & 49.8 & 39.5 & 35.3 \\
\hline
\end{tabular}

The results of this paper confirm that, due to the long-term trend of global warming, there is a higher chance of dry conditions than of wet conditions [106,107]. This is a critical issue for an agricultural region, such as Calabria, that suffers climate change [108-110], which is a major driver of agricultural and meteorological drought. In fact, precipitation and temperature anomalies caused by climate change will induce agro-meteorological drought [111]. In addition, water is usually significantly contaminated by organic matter derived from agricultural production and sewage, which may further aggravate the agricultural drought risk [112].

\section{Conclusions}

Unlike most natural hazards such as earthquakes and cyclones, both of which can strike quickly, drought does not usually have a sudden beginning or end. It is an insidious hazard caused by a period of abnormally dry weather, persisting long enough to produce a serious hydrologic imbalance. While a drought is unlikely to cause human deaths in most developed countries, a drought in a developing country without adequate access to aid can be devastating. In fact, drought can often be a natural hazard with the biggest economic impact, resulting in very costly and dramatic impacts on the environment such as stock losses, vulnerability to fires (especially in forested areas), crop damage, soil erosion, power blackouts if your community is reliant on electricity from hydro dams, and water supply shortages. The severity of a drought depends upon the degree of moisture deficiency, duration, and size of the affected area.

Monitoring dry and wet periods using meteorological indices, such as rainfall, is an essential component for drought preparedness. The variability of the rainfall is intrinsically present in its process, and it places uncertainties on projections. The use of the stochastic approach and the simulation procedure can effectively generate the variability of the rainfall process, and addresses the problem of quantity and reliability of the data used to fit the rainfall distribution. In the present paper, a model of monthly precipitation has been proposed. It adopts variable transformations, finalized to the deseasonalization and to Gaussianization of the monthly rainfall process, and includes a procedure for testing the autocorrelation. The model provided a good representation of the monthly rainfall for the selected 12 rain gauges of Calabria (Southern Italy). For this reason, $10^{4}$-year-long synthetic 
series have been generated for each rain gauge through a Monte Carlo procedure, and dry and wet periods in the region of Calabria were analyzed using the SPI applied to the simulated series. The index was calculated at two different time scales: 3-month SPI, which reflects short and medium-term moisture conditions, and 12-month SPI, which is linked to long-term precipitation patterns and can have an impact on streamflows, reservoir levels, and even groundwater levels. The occurrence probabilities of extreme, severe and moderate wet and dry conditions have been evaluated for each month, and compared with the corresponding probability classes commonly adopted in the literature. The comparison evidenced some differences, in particular for the 12-month SPI, for which higher probability values for dry conditions and lower probability values for wet conditions have been detected. Analogous results, as further confirmation of the good representation provided by the proposed model, have been obtained by means of the application of the DSI, based on the accumulated monthly rainfall deficits evaluated through the precipitation anomalies.

The advantage of the proposed model is that the stochastic approach overcomes the problems of quantity and reliability of the data, and can well reproduce the statistical characteristics of observed data, thus allowing a better prediction of the occurrence probabilities of extreme dry/wet conditions. Moreover, the stochastic model has the advantage of being applicable everywhere and for any gauge, because it does not depend on station altitude and climatic zone. For its characteristics, the model can also be applied to precipitation monthly grids, but this application depends on the grid size. In fact, the whole procedure is highly time-consuming, and its application is not recommended for too detailed grid sizes. Anyway, the proposed model can be considered an attractive tool for management decision-making, allowing the identification of a drought risk. Finally, properly adapted, the model can also be applied together with the climate projection obtained from global circulation models as a reliable tool for drought estimation in a changing climate.

Author Contributions: Beniamino Sirangelo conceived and designed the stochastic modeling; Tommaso Caloiero analyzed the data and performed the applications; Roberto Coscarelli and Ennio Ferrari contributed to the results and discussion; all the Authors wrote the paper.

Conflicts of Interest: The authors declare no conflict of interest.

\section{References}

1. Austin, R.B.; Cantero-Martínez, C.; Arrúe, J.L.; Playán, E.; Cano-Marcellán, P. Yield rainfall relationships in cereal cropping systems in the Ebro river valley of Spain. Eur. J. Agron. 1998, 8, 239-248. [CrossRef]

2. Quiring, S.M.; Papakryiakou, T.N. An evaluation of agricultural drought indices for the Canadian prairies. Agric. Forest Meteorol. 2003, 118, 49-62. [CrossRef]

3. Kogan, F. Droughts of the late 1980s in the United States as derived from NOAA Polar-Orbiting Satellite data. Bull. Am. Meteorol. Soc. 1995, 76, 655-668. [CrossRef]

4. Kogan, F. Global drought watch from space. Bull. Am. Meteorol. Soc. 1997, 78, 621-636. [CrossRef]

5. Abrams, M.D.; Ruffuer, M.C.; Morgan, T.A. Tree-ring responses to drought across species and contrasting sites in the ridge and valley of central Pennsylvania. Forest Sci. 1998, 44, 550-558.

6. Orwing, D.A.; Abrams, M.D. Variation in radial growth responses to drought among species site and canopy strata. Trees 1997, 11, 474-484. [CrossRef]

7. Coscarelli, R.; Caloiero, T.; Minervino, I.; Sorriso-Valvo, M. Map of sensitivity to desertification of an high productivity area in Southern Italy. J. Maps 2015. [CrossRef]

8. Nicholson, S.E.; Tucker, C.J.; Ba, M.B. Desertification drought and surface vegetation: An example from the west African Sahel. Bull. Am. Meteorol. Soc. 1998, 79, 815-829. [CrossRef]

9. Morales, A.; Olcina, J.; Rico, A.M. Diferentes persepciones de la sequía en España: Adaptación catastrofismo e intentos de corrección. Investig. Geogr. 2000, 23, 5-46. [CrossRef]

10. García, R.V. Nature Pleads Not Guilty; Pergamon Press: Oxford, UK, 1984.

11. Kanti, B. Coping mechanisms practised by drought victims (1994/1995) in north Bengal, Bangladesh. Appl. Geogr. 1998, 18, 355-373.

12. Cooper, G.; McGechan, M.; Vinten, A. The influence of a changed climate on soil workability and available workdays in Scotland. J. Agric. Eng. Res. 1997, 68, 253-269. [CrossRef] 
13. Earl, R. Prediction of trafficability and workability from soil moisture deficit. Soil Tillage Res. 1997, 40, 155-168. [CrossRef]

14. Falloon, P.D.; Betts, R.A. The impact of climate change on global river flow in HadGEM1 simulations. Atmos. Sci. Lett. 2006, 7, 62-68. [CrossRef]

15. Finlayson, J.; Betteridge, K.; MacKay, A.; Thorrald, B.; Singleton, P.; Costall, D. A simulation model of the effects of cattle treading on pasture production on North Island, New Zealand, Hill Land. N. Z. J. Agric. Res. 2002, 45, 255-272. [CrossRef]

16. Montanarella, L. Trends in land degradation in Europe. In Climate and Land Degradation; Sivakumar, M.V.K., Ndegwa, N., Eds.; Springer: Heidelberg, Germany, 2007; pp. 83-104.

17. Webb, J.; Anthony, S.; Brown, L.; Lyons-Visser, H.; Ross, C.; Cottril, B.; Johnson, D.; Scholefield, D. The impact of increasing the length of the cattle grazing season on emissions of ammonia and nitrous oxide and on nitrate leaching in England and Wales. Agric. Ecosyst. Environ. 2005, 105, 307-321. [CrossRef]

18. Anagnostopoulou, C.H.R.; Maheras, P.; Karacostas, T.; Vafiadis, M. Spatial and temporal analysis of dry spells in Greece. Theor. Appl. Climatol. 2003, 74, 77-91. [CrossRef]

19. Caloiero, T.; Coscarelli, R.; Ferrari, E.; Sirangelo, B. Analysis of dry spells in Southern Italy (Calabria). Water 2015, 7, 3009-3023. [CrossRef]

20. Chapman, T. Stochastic models for daily rainfall in the Western Pacific. Math. Comput. Simul. 1997, 43, 351-358. [CrossRef]

21. Deni, S.M.; Jemain, A.A.; Ibrahim, K. The best probability models for dry and wet spells in Peninsular Malaysia during monsoon seasons. Int. J. Climatol. 2010, 30, 1194-1205. [CrossRef]

22. Di Giuseppe, E.; Vento, D.; Epifani, C.; Esposito, S. Analysis of dry and wet spells from 1870 to 2000 in four Italian sites. Geophys. Res. Abstr. 2005, 7, 07712.

23. Dobi-Wantuch, I.; Mika, J.; Szeidl, L. Modeling wet and dry spells with mixture distributions. Meteorol. Atmos. Phys. 2000, 73, 245-256. [CrossRef]

24. Sirangelo, B.; Caloiero, T.; Coscarelli, R.; Ferrari, E. A stochastic model for the analysis of the temporal change of dry spells. Stoch. Environ. Res. Risk. Assess. 2015, 29, 143-155. [CrossRef]

25. Phillips, I.D.; McGregor, G.R. The utility of a drought index for assessing the drought hazard in Devon and Cornwall, South West England. Meteorol. Appl. 1998, 5, 359-372. [CrossRef]

26. Wilks, D.S. Interannual variability and extreme-value characteristics of several stochastic daily precipitation models. Agric. Forest Meteorol. 1999, 93, 153-169. [CrossRef]

27. Tsakiris, G.; Pangalou, D.; Vangelis, H. Regional drought assessment based on the Reconnaissance Drought Index (RDI). Water Resour. Manag. 2007, 21, 821-833. [CrossRef]

28. Wilhite, D.A.; Hayes, M.J.; Svodoba, M.D. Drought monitoring and assessment in the US. In Drought and Drought Mitigation in Europe; Voght, J.V., Somma, F., Eds.; Kluwers: Dordrecht, The Netherlands, 2000; pp. 149-160.

29. Khan, S.; Gabriel, H.F.; Rana, T. Standard precipitation index to track drought and assess impact of rainfall on watertables in irrigation areas. Irrig. Drain. Syst. 2008, 22, 159-177. [CrossRef]

30. Logan, K.E.; Brunsell, N.A.; Jones, A.R.; Feddema, J.J. Assessing spatiotemporal variability of drought in the US central plains. J. Arid Environ. 2010, 74, 247-255. [CrossRef]

31. Manatsa, D.; Mukwada, G.; Siziba, E.; Chinyanganya, T. Analysis of multidimensional aspects of agricultural droughts in Zimbabwe using the Standardized Precipitation Index (SPI). Theor. Appl. Climatol. 2010, 102, 287-305. [CrossRef]

32. Patel, N.R.; Yadav, K. Monitoring spatio-temporal pattern of drought stress using integrated drought index over Bundelkhand region; India. Nat. Hazards 2015, 77, 663-677. [CrossRef]

33. Raziei, T.; Saghafian, B.; Paulo, A.A.; Pereira, L.S.; Bordi, I. Spatial patterns and temporal variability of drought in western Iran. Water Resour. Manag. 2009, 23, 439-455. [CrossRef]

34. Xingcai, L.; Zongxue, X.U.; Bo, L. Spatio-temporal characteristics of Standardized Precipitation Index in the Taihu Basin during 1951-2000. Wuhan Univ. J. Nat. Sci. 2009, 14, 518-524.

35. Zhai, L.; Feng, Q. Spatial and temporal pattern of precipitation and drought in Gansu province northwest China. Nat. Hazards 2009, 49, 1-24. [CrossRef]

36. Livada, I.; Assimakopoulos, V.D. Spatial and temporal analysis of drought in Greece using the Standardized Precipitation Index (SPI). Theor. Appl. Climatol. 2007, 89, 143-153. [CrossRef] 
37. Sönmez, F.K.; Kömüscü, A.Ü.; Erkan, A.; Turgu, E. An analysis of spatial and temporal dimension of drought vulnerability in Turkey using the Standardized Precipitation Index. Nat. Hazards 2005, 35, 243-264. [CrossRef]

38. Vicente-Serrano, S.M. Differences in spatial patterns of drought on different time sales an analysis of the Iberian Peninsula. Water Resour. Manag. 2006, 20, 37-60. [CrossRef]

39. Vergni, L.; Todisco, F. Spatio-temporal variability of precipitation temperature and agricultural drought indices in Central Italy. Agric. Forest Meteorol. 2011, 151, 301-313. [CrossRef]

40. Bonaccorso, B.; Bordi, I.; Cancelliere, A.; Rossi, G.; Sutera, A. Spatial variability of drought: An analysis of SPI in Sicily. Water Resour. Manag. 2003, 17, 273-296. [CrossRef]

41. Buttafuoco, G.; Caloiero, T. Drought events at different timescales in Southern Italy (Calabria). J. Maps 2014, 10, 529-537. [CrossRef]

42. Buttafuoco, G.; Caloiero, T.; Coscarelli, R. Analyses of drought events in Calabria (Southern Italy) using standardized precipitation index. Water Resour. Manag. 2015, 29, 557-573. [CrossRef]

43. Capra, A.; Scicolone, B. Spatiotemporal variability of drought on a short-medium time scale in the Calabria Region (Southern Italy). Theor. Appl. Climatol. 2012, 3, 471-488. [CrossRef]

44. Capra, A.; Consoli, S.; Scicolone, B. Long-term climatic variability in Calabria and effects on drought and agrometeorological parameters. Water Resour. Manag. 2013, 27, 601-617. [CrossRef]

45. Mendicino, G.; Senatore, A.; Versace, P. A Groundwater Resource Index (GRI) for drought monitoring and forecasting in a Mediterranean climate. J. Hydrol. 2008, 357, 282-302. [CrossRef]

46. Rossi, G.; Cancelliere, A. Early warning of drought: Development of a drought bulletin for Sicily. In Proceedings of the 2nd International Conference: New Trends in Water and Environmental Engineering for Safety and Life: Ecocompatible Solutions for Aquatic Environments, Capri, Italy, 24-28 June 2002.

47. Wu, H.; Hayes, M.J.; Wilhite, D.A.; Svoboda, M.D. The effect of the length of record on the standardized precipitation index calculation. Int. J. Climatol. 2005, 25, 505-520. [CrossRef]

48. Mishra, A.K.; Singh, V.P. Drought modeling-A review. J. Hydrol. 2011, 403, 157-175. [CrossRef]

49. Zolina, O.; Simmer, C.; Belyaev, K.; Sergey, K.; Gulev, S.; Koltermann, P. Changes in the duration of European wet and dry spells during the last 60 years. J. Clim. 2013, 26, 2022-2047. [CrossRef]

50. Güven, O. A simplified semiempirical approach to probabilities of extreme hydrologic droughts. Water Resour. Res. 1983, 19, 441-453. [CrossRef]

51. Mathier, L.; Perreault, L.; Bobée, B.; Ashkar, F. The use of geometric and gamma-related distributions for frequency analysis of water deficit. Stoch. Hydrol. Hydraul. 1992, 6, 239-254. [CrossRef]

52. Sen, Z. Run-sums of annual streamflow series. J. Hydrol. 1977, 35, 311-324. [CrossRef]

53. Sen, Z. Regional drought and flood frequency analysis theoretical consideration. J. Hydrol. 1980, 46, $265-279$. [CrossRef]

54. Sharma, T. Estimation of drought severity on independent and dependent hydrologic series. Water Resour. Manag. 1995, 11, 35-49. [CrossRef]

55. Shiau, J.T.; Shen, H.W. Recurrence analysis of hydrologic droughts of differing severity. J Water Resour. Plan. Manag. 2001, 127, 30-40. [CrossRef]

56. Zelenhasìc, E.; Salvai, A. A method of streamflow drought analysis. Water Resour. Res. 1987, 23, $156-168$. [CrossRef]

57. Gupta, V.; Duckstein, L. Droughts as extreme distributions from a point rainfall process. Water Resour. Res. 1975, 11, 221-228. [CrossRef]

58. Cancelliere, A.; Salas, J.D. Drought length properties for periodic-stochastic hydrologic data. Water Resour. Res. 2004, 40, W02503. [CrossRef]

59. Sirangelo, B.; Caloiero, T.; Coscarelli, R.; Ferrari, E. Stochastic Analysis of Long Dry Spells in Calabria (Southern Italy). Available online: http:/ /link.springer.com/article/10.1007/s00704-015-1662-0 (accessed on 25 January 2016).

60. Wilks, D.S.; Wilby, R.L. The weather generation game: A review of stochastic weather models. Prog. Phys. Geogr. 1999, 23, 329-357. [CrossRef]

61. Brissette, F.P.; Khalili, M.; Leconte, R. Efficient stochastic generation of multi-site synthetic precipitation data. J. Hydrol. 2007, 345, 121-133. [CrossRef]

62. Iyengar, R.N. Stochastic modelling of monthly rainfall. J. Hydrol. 1982, 57, 375-387. [CrossRef] 
63. Semenov, M.A.; Porter, J.R. Climatic variability and the modelling of crop yields. Agric. Forest Meteorol. 1995, 73, 265-283. [CrossRef]

64. Apipattanavis, S.; Podestà, G.; Rajagopalan, B.; Katz, R.W. A semiparametric multivariate and multisite weather generator. Water Resour. Res. 2007, 43, W11401. [CrossRef]

65. Bardossy, A.; Pegram, G. Copula based multisite model for daily precipitation simulation. Hydrol. Earth Syst. Sci. 2009, 13, 2299-2314. [CrossRef]

66. Bordoy, R.; Burlando, P. Stochastic downscaling of precipitation to high-resolution scenarios in orographically complex regions. Part 1: Model evaluation. Water Resour. Res. 2014, 50, 540-561. [CrossRef]

67. Burton, A.; Kilsby, C.; Fowler, H.; Cowpertwait, P.S.; O'Connell, P. RainSim: A spatial temporal stochastic rainfall modelling system. Environ. Model. Softw. 2008, 23, 1356-1369. [CrossRef]

68. Cowpertwait, P.S.P.; Kilsby, C.; O'Connell, P. A space-time Neyman-Scott model of rainfall: Empirical analysis of extremes. Water Resour. Res. 2002, 38, 1-14. [CrossRef]

69. Cowpertwait, P.S.P. A spatial temporal point process model of rainfall for the Thames catchment; UK. J. Hydrol. 2006, 330, 586-595. [CrossRef]

70. Cowpertwait, P.S.P. A spatial-temporal point process model with a continuous distribution of storm types. Water Resour. Res. 2010, 46, W12507. [CrossRef]

71. Kang, B.; Ramirez, J.A. A coupled stochastic space-time intermittent random cascade model for rainfall downscaling. Water Resour. Res. 2010, 46, W10534. [CrossRef]

72. Paschalis, A.; Molnar, P.; Fatichi, S.; Burlando, P. On temporal stochastic modeling of precipitation; nesting models across scales. Adv. Water Resour. 2014, 63, 152-166.

73. Peleg, N.; Morin, E. Stochastic convective rain-field simulation using a high-resolution synoptically conditioned weather generator (HiReS-WG). Water Resour. Res. 2014, 50, 2124-2139. [CrossRef]

74. Serinaldi, F. A multisite daily rainfall generator driven by bivariate copula-based mixed distributions. J. Geophys. Res. 2009, 114, D10103. [CrossRef]

75. Steinschneider, S.; Brown, C. A semiparametric multivariate; multisite weather generator with low-frequency variability for use in climate risk assessments. Water Resour. Res. 2013, 49, 7205-7220. [CrossRef]

76. Hayhoe, H.N. Improvements of stochastic weather data generators for diverse climates. Clim. Res. 2000, 14, 75-87. [CrossRef]

77. Liu, J.; Williams, J.R.; Wang, X.; Yang, H. Using MODAWEC to generate daily weather data for the EPIC model. Environ. Model. Softw. 2009, 24, 655-664. [CrossRef]

78. Richardson, C.W. Stochastic simulation of daily precipitation temperature and solar radiation. Water Resour. Res. 1981, 17, 182-190. [CrossRef]

79. Sharma, A.; Lall, U. A nonparametric approach for daily rainfall simulation. Math. Comput. Simulat. 1999, 48, 361-371. [CrossRef]

80. Srikanthan, R.; McMahon, T.A. Stochastic Generation of Rainfall and Evaporation Data; Technical Report 84; Australian Water Resources Council Department of Resources and Energy: Canberra, Australia, 1985.

81. Srikanthan, R.; Harrold, T.I.; Sharma, A.; McMahon, T.A. Comparison of two approaches for generation of daily rainfall data. Stoch. Environ. Res. Risk. Assess. 2005, 19, 215-226. [CrossRef]

82. Wan, H.; Zhang, X.; Barrow, E.M. Stochastic modelling of daily precipitation for Canada. Atmos. Ocean 2005, 43, 23-32. [CrossRef]

83. Woolhiser, D.A. Modelling daily precipitation-Progress and problems. In Statistics in the Environmental and Earth Sciences; Walden, A.T., Guttorp, P., Eds.; Edward Arnold: London, UK, 1992; pp. 71-89.

84. Zheng, X.; Katz, R.W. Mixture model of generalized chain-dependent processes and its application to simulation of interannual variability of daily rainfall. J. Hydrol. 2008, 349, 191-199. [CrossRef]

85. Srikanthan, R.; McMahon, T.A. Stochastic generation of annual monthly and daily climate data: A review. Hydrol. Earth Syst. Sci. 2001, 5, 653-670. [CrossRef]

86. McKee, T.B.; Doesken, N.J.; Kleist, J. The relationship of drought frequency and duration to time scales. In Proceedings of the 8th Conference on Applied Climatology, Anaheim, CA, USA, 17-22 January 1993; pp. 179-184.

87. Angelidis, P.; Maris, F.; Kotsovinos, N.; Hrissanthou, V. Computation of drought index SPI with Alternative Distribution Functions. Water Resour. Manag. 2012, 26, 2453-2473. [CrossRef]

88. Stagge, J.H.; Tallaksen, L.M.; Gudmundsson, L.; van Loon, A.F.; Stahl, K. Candidate distribution for climatological drought indices (SPI and SPEI). Int. J. Climatol. 2015, 35, 4027-4040. [CrossRef] 
89. Mason, D.M.; Schuenemeyer, J.H. A modified Kolmogorov-Smirnov test sensitive to tail alternatives. Ann. Stat. 1983, 11, 933-946. [CrossRef]

90. Crutcher, H.L. A note on the possible misuse of the Kolmogorov-Smirnov test. J. Appl. Meteorol. 1975, 14, 1600-1603. [CrossRef]

91. Steinskog, D.J.; Tjøstheim, D.B.; Kvamstø, N.G. A cautionary note on the use of the Kolmogorov-Smirnov test for normality. Mon. Weather Rev. 2007, 135, 1151-1157. [CrossRef]

92. Wu, H.; Svoboda, M.D.; Hayes, M.J.; Wilhite, D.A.; Wen, F. Appropriate application of the standardized precipitation index in arid locations and dry seasons. Int. J. Climatol. 2007, 27, 65-79. [CrossRef]

93. Bryant, S.J.; Arnell, N.W.; Law, F.M. The longterm context for the current hydrological drought. In Proceedings of the IWEM Conference on the Management of Scarce Water Resources, Brighton, UK, 13-14 October 1992.

94. Blenkinsop, S.; Fowler, H.J. Changes in drought frequency, severity and duration for the British Isles projected by the PRUDENCE regional climate models. J. Hydrol. 2007, 342, 50-71. [CrossRef]

95. Blenkinsop, S.; Fowler, H.J. Changes in European drought characteristics projected by the PRUDENCE regional climate models. Int. J. Climatol. 2007, 27, 1595-1610. [CrossRef]

96. Bernstein, S.; Bernstein, R. Elements of Statistics: II-Inferential Statistics; McGraw-Hill: New York, NY, USA, 1999.

97. Priestly, M.B. Spectral Analysis and Time Series; Academic Press: London, UK, 1994.

98. Anderson, R.L. Distribution of serial correlation coefficient. Ann. Math. Stat. 1942, 13, 1-13. [CrossRef]

99. Haan, C.T. Statistical Methods in Hydrology; Iowa State University Press: Ames, IA, USA, 1997.

100. Ferrari, E.; Caloiero, T.; Coscarelli, R. Influence of the north Atlantic Oscillation on winter rainfall in Calabria (Southern Italy). Theor. Appl. Climatol. 2013, 114, 479-494. [CrossRef]

101. Caloiero, T.; Pasqua, A.A.; Petrucci, O. Damaging hydrogeological events: A procedure for the assessment of severity levels and an application to Calabria (Southern Italy). Water 2014, 6, 3652-3670. [CrossRef]

102. Coscarelli, R.; Caloiero, T. Analysis of daily and monthly rainfall concentration in Southern Italy (Calabria region). J. Hydrol. 2012, 416-417, 145-156. [CrossRef]

103. Brunetti, M.; Caloiero, T.; Coscarelli, R.; Gullà, G.; Nanni, T.; Simolo, C. Precipitation variability and change in the Calabria region (Italy) from a high resolution daily dataset. Int. J. Climatol. 2012, 32, 57-73. [CrossRef]

104. Craddock, J.M. Methods of comparing annual rainfall records for climatic purposes. Weather 1979, 34, 332-346. [CrossRef]

105. Press, M.H.; Teukolsky, S.A.; Vetterling, W.T.; Flannery, B.P. Numerical Recipes in C: The Art of Scientific Computing, 2nd ed.; Cambridge University Press: Cambridge, UK, 1997.

106. Giordano, R.; Preziosi, E.; Romano, E. Integration of local and scientific knowledge to support drought impact monitoring: Some hints from an Italian case study. Nat. Hazards 2013, 69, 523-544. [CrossRef]

107. Wu, J.; He, B.; Lu, A.; Zhou, L.; Liu, M.; Zhao, L. Quantitative assessment and spatial characteristics analysis of agricultural drought vulnerability in China. Nat. Hazards 2011, 56, 785-801. [CrossRef]

108. Caloiero, T.; Buttafuoco, G.; Coscarelli, R.; Ferrari, E. Spatial and temporal characterization of climate at regional scale using homogeneous monthly precipitation and air temperature data: An application in Calabria (Southern Italy). Hydrol. Res. 2015, 46, 629-646. [CrossRef]

109. Caloiero, T.; Callegari, G.; Cantasano, N.; Coletta, V.; Pellicone, G.; Veltri, A. Bioclimatic Analysis in a Region of Southern Italy (Calabria). Available online: http://www.tandfonline.com/ doi/abs/10.1080/11263504.2015.1037814 (accessed on 25 January 2016).

110. Pellicone, G.; Caloiero, T.; Coletta, V.; Veltri, A. Phytoclimatic map of Calabria (Southern Italy). J. Maps 2014, 10, 109-113. [CrossRef]

111. Li, Y.; Gu, W.; Cui, W.; Chang, Z.; Xu, Y. Exploration of copula function use in crop meteorological drought risk analysis: A case study of winter wheat in Beijing, China. Nat. Hazards 2015, 77, 1289-1303. [CrossRef]

112. Xu, X.; Ge, Q.; Zheng, J.; Dai, E.; Zhang, X.; He, S.; Liu, G. Agricultural drought risk analysis based on three main crops in prefecture-level cities in the monsoon region of east China. Nat. Hazards 2013, 66, 1257-1272. [CrossRef]

(C) 2016 by the authors; licensee MDPI, Basel, Switzerland. This article is an open access article distributed under the terms and conditions of the Creative Commons by Attribution (CC-BY) license (http://creativecommons.org/licenses/by/4.0/). 